\title{
In situ optimization methodology for ground source heat pump systems: upgrade to ensure user comfort
}

\author{
J. Cervera-Vázquez, C. Montagud*, J. M. Corberán \\ Instituto de Ingeniería Energética, Universitat Politècnica de València, Camino de Vera s/n, 46022 \\ Valencia, Spain \\ *Corresponding author. Tel.: +34 963879910. E-mail address: carmonmo@iie.upv.es
}

\begin{abstract}
Ground source heat pump systems have been proved to be one of the most efficient systems for heating and cooling in buildings. However, an optimal energy performance depends on a good control of the auxiliaries, which stand for an important part of the total energy consumption. The authors previously developed an experimental in situ optimization methodology for the water circulation pumps frequency of ground source heat pump systems when single stage and multi-stage ON/OFF regulation is employed. However, the user comfort was not completely met under extreme weather conditions during summer. This paper presents the upgrading of this energy optimization strategy combining circulation pumps frequency variation and building supply temperature compensation in order to ensure the user comfort while keeping high energy savings. Experimental results show that the user comfort is met by means of this new methodology and the energy savings (33\%) are even higher than those obtained with the previous methodology.
\end{abstract}

Keywords: Heating/cooling systems; ground source heat pump; energy efficiency;

\section{INTRODUCTION}

Ground source heat pump (GSHP) systems can lead to a 40\% savings in annual electricity consumption, in comparison to air to water conventional heat pumps [1]. In order to achieve an optimal performance of these systems, a proper operation of all the components of the system as a whole should be carried out. Over the last years, research has focused on capacity control, mainly by means of variable speed compressors. For instance, Fahlén and Karlsson compared control for ON/OFF compressor with variable speed control for a brine-to-water heat pump ([2] and [3]). In addition to this, the importance of the 
auxiliaries in space heating and cooling systems was highlighted by several studies ([4], [5] and [6]). This becomes especially important in GSHP systems, where two circulation pumps are required.

In [7] a control strategy was developed to predict optimal ground source heat pump water flow rates under part load operation, and it was evaluated through a simulation model for single speed and tandem speed heat pumps. In [8] the results of a simulation model were compared with experimental data in a GSHP installation with variable speed compressor, variable speed water circulation pumps and variable speed fans in the coils.

The authors previously developed an experimental in situ optimization methodology for the water circulation pumps frequency of ground source heat pump systems when single stage [9] and multi-stage [10] ON/OFF regulation is employed. The results from this methodology were combined in an energy optimization algorithm together with an outdoor temperature reset (or temperature compensation) strategy in order to keep both the setpoint of the heat pump and the flow rates of the water circulation pumps at an optimal combination [11]. The key point to find this optimal combination was to consider the pump circulation rates optimizing the total power consumption of the system and not only the heat pump power consumption. This optimized control was compared to a standard control, and energy savings around 30\% were obtained depending on the period analyzed ([10] and [11]).

However, although an important enhancement of the energy performance of the system was observed when applying the optimized control, the use along several seasons led to some complaints from the users. After analyzing carefully the operation of the system and all the working conditions, it was detected that the user comfort was not met in extreme weather conditions during summer mainly during July, as the indoor temperature and relative humidity observed in several rooms during these extreme days in summer took values around $27^{\circ} \mathrm{C}$ and $70 \%$ respectively. No complaints were received about the heating season comfort. This paper describes the reason why the former algorithm did not meet the user comfort and proposes a new integrated optimization strategy in order to make the system operate at its optimal point from the point of view of energy performance while being able to meet the user comfort at any time. The experimental measurements presented in this paper have been analyzed for cooling mode. Future analysis will be done during the next heating season. 


\section{BACKGROUND}

\subsection{GEOTHERMAL EXPERIMENTAL PLANT}

The geothermal installation studied in this paper was built in year 2005 in the framework a European project called GEOCOOL (Geothermal Heat Pump for Cooling and Heating along European Areas, contract number NNE5-2001-00847). Since then, the installation has been completely monitored. In the Framework of another European project, GROUND-MED (Advanced ground source heat pump systems for heating and cooling in Mediterranean climate, contract number TREN/FP7EN/218895), different energy optimization studies were carried out during years 2009 to 2013. The research work presented in this paper has been developed in this framework.

The experimental plant air-conditions a set of spaces in the Department of Applied Thermodynamics at the Universitat Politècnica de València, Spain, covering a total floor area of approximately $250 \mathrm{~m}^{2}$, and includes a corridor, nine offices (located on the east façade of the building), a computer room and a service room with office equipment and other internal loads. Each office, along with the service room, is equipped with one fan coil, except for the computer room which has two installed fan coils. The corridor is not air conditioned. Each fan coil can be individually regulated by means of a thermostat; and comfort temperature and fan speed can be manually selected by the user. The control for each fan coil is governed by a three

way valve that allows the heating/cooling water to be modulated through the fan coil. The valve is controlled by the thermostat of the room.

Each room has a fan coil unit supplied by the GSHP system. The GSHP system mainly consists of a reversible water-to water GSHP, a ground source heat exchanger and two hydraulic loops (one for the internal loop coupled to the building, and another one for the external loop coupled to the ground) as shown in the diagram of the installation in Figure 1. The GSHP currently installed, is a prototype unit developed and manufactured in the framework of the GROUND-MED. It consists of a water-to-water reversible GSHP, which uses R410A as refrigerant. The heat pump is reversible both on the refrigerant and on the secondary fluid circuits thanks to the use of water reversing valves, in such a way that it always works in counter current conditions resulting in a higher efficiency. The nominal heating and cooling capacities are $18 \mathrm{~kW}\left(35^{\circ} \mathrm{C}\right.$ return $/ 17^{\circ} \mathrm{C}$ return $)$ and $15.4 \mathrm{~kW}\left(14^{\circ} \mathrm{C}\right.$ return $/ 25^{\circ} \mathrm{C}$ return $)$ respectively. In order to better 
adapt the GSHP capacity to the building thermal load, the GSHP has two scroll compressors of the same capacity working in tandem. The evaporator and condenser are two brazed plate heat exchangers of the same geometry with 42 plates each. The ground source heat exchanger (GSHX) consists of a vertical borehole heat exchanger (grid of $2 \times 3$ boreholes, 50 meter deep, 3 meter separated from each other; each borehole contains a single polyethylene Utube of $25.4 \mathrm{~mm}$ internal diameter, with a70mm separation between the upward and downward tubes.

As shown in Figure 1, the system is divided into two hydraulic circuits. The internal one consists of 12 parallel-connected fan coils units, an internal hydraulic loop and a water storage tank. The external one consists of the ground source heat exchanger which is coupled to the heat pump by an external hydraulic loop. The system operates from 7 am to 8 pm during 5 days per week.

Both circuits have circulation pumps in order to pump the water to the fan coil units (ICP; nominal values at $50 \mathrm{~Hz}: 3180 \mathrm{~kg} / \mathrm{h}, 0.63 \mathrm{~kW}$ ) and the GSHX (ECP; nominal values at $50 \mathrm{~Hz}: 2650 \mathrm{~kg} / \mathrm{h}, 0.36 \mathrm{~kW})$. The internal pump operates continuously along the day, whereas the external pump only works when at least one of the compressors of the heat pump is running. The water flow rate in both circuits can be varied by means of two frequency inverters.

A network of sensors was set up so that the installation is completely monitored: water temperatures (fourwire PT100 with accuracy $\pm 0.1^{\circ} \mathrm{C}$.), mass flow rates (Danfoss flow meter model massflo MASS 6000 with accuracy $<0.1 \%$ ) and power consumptions (Gossen Metrawatt power meter model A2000 with accuracy $\pm 0.5 \%$ ). Further details on system description can be found in previous publications ([10], [11] and [12]).

\subsection{IN SITU OPTIMIZATION METHODOLOGY FOR THE WATER CIRCULATION PUMPS FREQUENCY}

The authors previously developed an experimental in situ optimization methodology for the water circulation pumps frequency [10]. Its main advantage is that it is based on experimental measurements and it can be carried out in situ at any installation. Therefore, it is able to take into account the real characteristics of the installation as well as real operating conditions. A summary of this methodology, which consists of three steps, is presented in this subsection. 
The first step consists of several experimental tests of pseudo-random sequence of frequency steps, sweeping both circulation pumps frequencies in the range of operating frequencies (from $20 \mathrm{~Hz}$ to $55 \mathrm{~Hz}$ ). Through this step it is intended to characterize the performance of the system during the ON time operation of the compressor. Since the heat pump consists of two compressors working in tandem, the tests must be repeated when there is only one compressors cycling ON/OF or one compressor continuously running and the other one cycling ON/OFF.

The second step consists of analyzing the results obtained from step 1, estimating the system COP in quasi-steady state conditions (only the ON cycle) and finally representing the values of the COP in a contour map as a function of both circulation pumps frequencies.

The third step allows taking into account the influence of the internal circulation pump and the parasitic losses during the OFF cycle calculating, from the quasi-steady state performance maps obtained in step 2 of the methodology, the optimal frequencies as a function of the thermal demand of the building. The thermal demand of the building is represented here by the partial load ratio of the system $(\alpha)$, which can be defined as the relation between the instantaneous thermal load of the building and the heat pump capacity. This step finally provides the system performance factor as a function of the partial load ratio of the system for different values of both circulation pumps frequencies. A sample of the resulting contour maps is shown in Figure 2.

From the maps in Figure 2, expressions which provide the optimal values of both circulation pumps frequencies as a function of the partial load ratio can be obtained and implemented in the control board of the system. The mathematical expressions obtained for cooling mode can be observed in Figure 3 . In order to complete the optimized control, the setpoint of the heat pump, which uses the building supply temperature in order to control the starts and stops of the compressors, is also varied according to a simple outdoor temperature reset strategy.

Figure 3 shows a flow diagram that indicates how this optimization algorithm works. The controlled variables are the temperature setpoint of the heat pump $\left(\mathrm{T}_{\mathrm{SB}}\right)$ and the frequency of both the internal ( $\left.\mathrm{f}_{\mathrm{ICP}}\right)$ and the external ( $\left.f_{\mathrm{ECP}}\right)$ circulation pumps. The measured variables are the ambient temperature $\left(\mathrm{T}_{\mathrm{amb}}\right)$ and the partial load ratio of the system $(\alpha)$. As it can be observed in the flow diagram presented in Figure 3, the temperature setpoint of the heat pump was determined as a function of the ambient temperature solely, and 
the higher the ambient temperature, the lower the temperature setpoint set at the heat pump controller. On the other hand, the circulation pumps frequencies were calculated as a function of the partial load ratio solely, as determined from the three-step methodology. As it can be observed in Figure 3, the higher the load ratio, the higher the values of frequency set in at the frequency inverters, and hence the water flowrates circulating through the hydraulic circuits.

As presented in [10], this optimized control was implemented in the control board of the system and tested on the geothermal experimental plant for a period of several months. Results showed that energy savings of $(31.70 \pm 0.07) \%$ were obtained by applying the optimized control, when comparing to a standard control consisting of a fixed value of frequency of $50 \mathrm{~Hz}$ for both circulation pumps and a setpoint of $10^{\circ} \mathrm{C}$ in cooling mode and $40^{\circ} \mathrm{C}$ in heating mode. However, it was found that user comfort was not met in extreme weather conditions during summer.

\section{CONTROLLED VARIABLES AND FAN COIL EFFECTIVENESS}

The explanation on why the former optimized control did not meet the user comfort lies in the fan coil effectiveness. Figure 4 shows for different values of the building supply temperature, how the effectiveness of the fan coil varies with the internal flow rate, for cooling mode. The air flow rate in the fan coil was

fixed to its nominal value ( $\quad$ ). The curves were obtained from the manufacturer of the fan coils, which provides a piece of software that includes a model of the fan coils based on experimental data taken at their laboratories. The following analysis is presented for cooling mode but would be analogous for heating mode.

As it is observed in figure 4, the effectiveness of the fan coil decreases not only when the supply temperature increases, but also and with more significance when the internal flow rate decreases. As presented in the previous section, when the former optimized control was applied, the setpoint of the heat pump was varied as a function of the ambient temperature, whereas the frequencies of both circulation pumps (and hence the flow rates) were varied as a function of the partial load ratio. However, both controls strategies were independent from each other. This would mostly explain the lack of comfort experimented by the users. When there were few people in the building in a hot day, although they needed to meet their cooling needs, the partial load ratio of the whole system was small, and the control system was setting low 
frequencies and thus low flow rates (see figure 3). Then, if the ambient temperature was not very high, the building supply temperature was not low enough and this resulted in the decrease of the fan coil effectiveness and in the fan coil not providing enough capacity as to cover the thermal load of the room, which turned into user discomfort.

Analyzing the same problem through equations, the thermal load for each room and the fan coil capacity can be expressed as in equations (1) and (2) respectively.

Where:

would be the overall heat transfer conductance of the room, including the internal gains and the solar irradiation in the room,

is the flow rate of air circulating through the coil in the fan coil, is the specific heat of air at constant pressure and is the effectiveness of the fan coil, which depends on the nominal heat capacity of the air (

$$
\text { ) and the heat capacity of water ( ). }
$$

In order to achieve user comfort, the fan coil capacity should cover the room thermal load, as expressed in equation (3).

This results in a supply building temperature that, in order to provide user comfort, should be lower than a certain value which will be given by equation (4).

Equation (4) provides the limit condition. Considering the design conditions of the fan coil (maximum ambient temperature , e.g. in Valencia, minimum building supply temperature , e.g. , and the maximum internal circulation pump flow rate), for which the fan coil has to provide comfort to the users in the worst case scenario (hottest day of the year), the inequation turns into equation (5). Under these conditions, the effectiveness of the fan coil will be maximum ( $\quad$ ). 
In order to simplify calculations, the assumption given by equation (6) was considered in the former control.

This assumption would be true in case that the effectiveness of the fan coil remained constant. However, as a result of the variation of the internal circulation pump frequency explained earlier for the former control, the water flow through the coil is modified. Consequently, equation (6) cannot be considered as true when varying the water flow rate entering the coil, as it will dramatically vary the effectiveness of the fan coil. Instead, equation (5) is solved for the of the room, resulting in equation (7).

Then, replacing the expression of the provided by equation (7) in equation (4) results in equation (8), which provides the building supply temperature required to achieve user comfort.

Where is the relation given by equation (9).

The curves presented in figure 4 were obtained by calculating some points from the software provided by the manufacturer of the fan coils. However, in order to use it for calculations later on in this paper, a mathematical expression that correlates the fan coil effectiveness with the internal frequency and the building supply temperature ( $\quad$ ) should be obtained. Equation (10) provides the maximum value of the building supply temperature required to achieve user comfort, taking into account the variation in the effectiveness produced by the internal water flow variation and the building supply temperature variation. Hence the water should be supplied at a temperature lower or equal to the value given by equation (10).

Analyzing figure 4, it can be observed that the fan coil effectiveness does not vary linearly with the flow rate, but presents a quadratic relation. However, this relation, which seems to be independent from the 
building supply temperature for small values of water flow rate, turns out to be different for greater flow rates. This means that it may exist a cross relation of flow rate and supply temperature. Finally, it seems that there is a linear relation of the effectiveness with the supply temperature as well. Considering all these observations, the following three expressions are proposed in order to find the correlation that best fits the fan coil data. The three proposed correlations are analyzed in figure 5 .

As it can be observed in figure 5a, the fact of neglecting the influence of the supply building temperature in equation (11), causes correlation (a) not to fit the data set very well for high values of the internal flow rate. This is shown in figure $5 \mathrm{~d}$, in which the deviation is higher than for the remaining correlations (figures $5 \mathrm{~d}$ and 5f). Regarding correlations (b) and (c), it can be observed in figures $5 \mathrm{~b}$ and $5 \mathrm{c}$ that both fit the data set in a similar way. That is why the conclusion is to choose correlation (b), because it provides similar accuracy to correlation (c) while simplifying calculations.

\section{INTEGRATED ENERGY OPTIMIZATION STRATEGIES}

The objective of the control algorithm is to optimize the energy performance of the system, represented by the system performance factor ( $\quad$ ). As presented in section 2.2, the value of the internal circulation pump frequency which optimizes the performance factor of the system was calculated, by means of the experimental methodology developed, in terms of the partial load ratio of the system ( ), and the building supply temperature was determined as a function of the ambient temperature $(\quad$ ) as a first control attempt. However, the influence of decreasing the internal water flow rate was not taken into account in the fan coil effectiveness, what resulted in the comfort of the user not being met. This happened because both strategies were uncoupled, that is to say, they worked independently of what each other did.

In order to find the optimal values of the controlled variables, namely the internal circulation pump frequency ( ) and the building supply temperature ( ), that optimize the performance factor of the system while being able to meet the user comfort, it is necessary to couple both strategies. In the former control, the supply building temperature was calculated as a function of the ambient temperature solely 
( ), whereas the internal frequency was determined considering only the partial load ratio

( ). Now both control parameters need to be determined as a function of both variables, the ambient temperature and the partial load ratio of the system ( and $)$.

For a start, the performance factor of the system will depend on the controlled variables: internal circulation pump frequency and supply building temperature ( $\quad$ ). Its variation can be expressed as the sum of the partial derivatives of the system performance factor with each one of the variables. This is mathematically expressed in equation (14).

Therefore, the variation of the system performance factor with the internal circulation pump frequency will be given by equation (15).

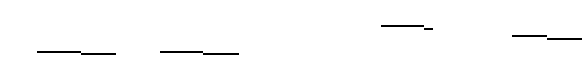

Finally, equaling this derivative to zero and solving the resulting equation (equation (16)) will provide the optimal value of the internal frequency taking into account not only the energy optimization of the system but also the user comfort.

Where:

(a) — is the partial derivative of the performance factor with the internal frequency for a given building supply temperature

(b) _ _ is the partial derivative of the performance factor with the building supply temperature for a given internal frequency and

(c) is the derivative of the performance factor with the internal frequency.

The first addend in equation (16) would provide the optimal internal circulation pump frequency for a given supply building temperature, as resulting from the methodology developed in [10], while the second one would provide the necessary correction with a view to meet the user comfort. In order to solve equation (16), each one of the addends in it will be determined first. 


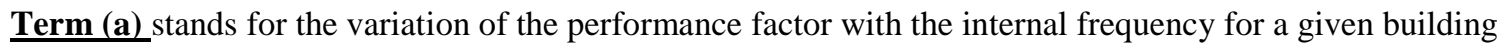
supply temperature. This variation is given by the PF maps resulting from the in situ methodology in [10]. The contour maps are obtained for a constant building supply temperature $\left(40^{\circ} \mathrm{C}\right.$ in the case of heating mode and $10^{\circ} \mathrm{C}$ in cooling mode). They show how the performance factor varies in terms of the circulation pumps frequencies and provide the optimal pair of frequencies. A sample of these maps is presented in figure 2 .

Since the intention is to obtain the variation of the system performance factor ( ) with the internal frequency ( ), the external frequency ( ) is fixed to its optimal value for each value of . Considering these optimal values of the external circulation pump frequency for each value of from 0.1 to 1 , figure 6 shows, for cooling mode, the system performance factor as a function of the internal frequency. The curves in figure 6, which show the variation of with the internal frequency, have been adjusted to cubic equations. The maximums in the curves turn out to be the optimal values for the internal frequency for each value of the partial load ratio resulting from the methodology summarized in section 2.2 (see curve in figure 3). Differentiating the resulting expressions will finally provide term (a). Term (b) stands for the variation of the performance factor with the building supply temperature for a given internal frequency. In order to calculate this term, the performance factor is determined for different values of the building supply temperature by means of equations (17) and (18). This is represented in figure 7a. Equations (17) and (18) were described by the authors in reference [10]. See reference [10] for more details.

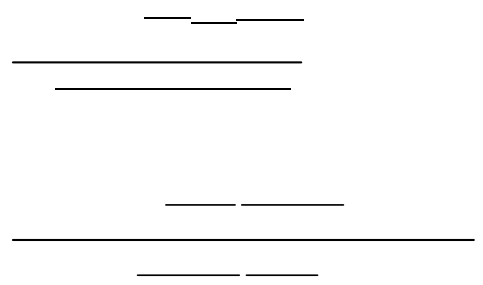

Then the expressions obtained, which are nearly linear, are differentiated to obtain term (b). In order to solve the partial derivative, the experimental correlations of the heat pump are considered [13]. The result is presented in figure $7 \mathrm{~b}$. Looking at the vertical axis, it can be observed that the analyzed partial derivative presents little variation. In order to simplify the control algorithm, an average value of 0.15 is considered 
for term (b). The possible deviations produced for considering this value (

in the value of

have been checked and a slight deviation of $\mathrm{Hz}$ in the resulting is produced. Therefore, the simplification is completely valid.

Term (c) stands for the variation of the performance factor with the internal frequency. This term is obtained by differentiating equation (10), including the corresponding expression for the effectiveness of the fan coil (correlation (b)), determined in section 3.

Considering terms (a), (b) and (c) in equation (16) and solving it for , the optimal value of the internal frequency is obtained. It should be noticed that the resulting expression is a $6^{\text {th }}$ order polynomial expression, hence the right root needs to be chosen.

Figure 8 shows the debugging of results for an example in which values of for the ambient temperature and for the partial load ratio are considered. Figures 8a to 8c show the different terms (a), (b) and (c), respectively, represented as a function of the internal frequency for the range of working frequencies, that is to say from $20 \mathrm{~Hz}$ to $55 \mathrm{~Hz}$. As it can be observed in figure 8a, presents an optimal value for the internal frequency at $23.8 \mathrm{~Hz}$ (intersection with the zero line). This value corresponds to the maximum of the curve for $\quad$ in figure 6 . In fact, this would be the resulting value for the optimal internal frequency if the in situ methodology for the circulation pumps frequency is applied as described in [10].

However, due to the correction introduced in order to take into account the user comfort, this value of frequency is corrected by the product of terms (b) and (c). Figure $8 \mathrm{~d}$ shows the representation of equation (16) as a function of the internal frequency, for the range of working frequencies. As it can be observed, the correction introduced turn the value of $23.8 \mathrm{~Hz}$ taken from figure $8 \mathrm{a}$ into an optimal value for the internal frequency of $33.7 \mathrm{~Hz}$, greater than the former one. Solving equation (14) as in the example presented, for different values of the partial load ratio ( $\quad$ ) and different values of the ambient temperature ( , figure 9 can be obtained. It shows the resulting value of the optimal internal frequency as a function of the partial load ratio of the system. The points marked with a black square correspond to the optimal frequency as directly calculated from the methodology summarized in section 2.2. The rest of the points represent the optimal 
frequency resulting from the new approach for different values of the ambient temperature in the range $24^{\circ} \mathrm{C}$ to $38^{\circ} \mathrm{C}$.

It can be observed in figure 9 that the higher the partial load ratio, the higher the resulting internal frequency. This is the same trend found in the former control (black squares). However, as a result of the new control strategy, the internal frequency now depends also on the ambient temperature. As it happens with the load, the higher the ambient temperature the higher the resulting frequency. The effect of the ambient temperature becomes less important for high values of the partial load ratio (when two compressors are running for )

It can also be observed that the correction of the frequency introduced in the new control is sometimes negative with respect to the former control (that is to say, the corrected frequency is lower than in the former control). This is because the ambient temperature is low and the load is not too big, so there is no need for higher flow rates that would result in higher fan coil capacity.

Once the optimal value of the internal frequency has been calculated, the next step consists of determining the corresponding value of the building supply temperature so that the user comfort is met.

Replacing the value obtained for the internal frequency in the corresponding correlation of the fan coil effectiveness and the numeric values for the rest of variables $(\quad \quad \quad \quad \quad=0.838$ ), equation (7) provides the value of the building supply temperature. Solving equation (10) for $\quad$ ( $2^{\text {nd }}$ order equation), for different values of the partial load ratio ( $\quad$ ) and different values

of the ambient temperature ( , figure 10 can be obtained.

The striped horizontal line at stands for the dew temperature in comfort conditions (

). The squares correspond to the values of the building supply temperature calculated by the former algorithm, which are similar to the values obtained by the new algorithm for . Finally, the rest of the points represent the resulting calculated by the new control for different values of the partial load ratio in the range 0.1 to 1 . It can be observed that the higher the ambient temperature, the lower the resulting building supply temperature. 
It can also be observed that the lower the partial load ratio, the lower the supply building temperature. This makes sense because lower values of the partial load ratio mean lower values of the internal frequency needed according to the optimization algorithm, what means that the building supply temperature has to decrease accordingly in order to keep the fan coil effectiveness and meet the user comfort. This resulting represents the highest possible value to be set in the heat pump in order to achieve user comfort, hence the water should be supplied to the fan coil units at a temperature lower or equal to the calculated values in order to meet the user comfort.

\section{IMPLEMENTATION OF THE NEW OPTIMIZED CONTROL}

When implementing an algorithm in a controller, the simpler the better. That is why, instead of programing the equations presented in previous sections, a simpler expression will be used. This expression comes from representing the points from figure 9 in a 3-dimensional graph. The target expression is a surface that fits all the points, the resulting values of the internal frequency as a function of both the partial load ratio and the ambient temperature ( $\quad$ ). Two different fitting surfaces for the different states in which the heat pump can work are produced: one compressor cycling on and off $(n=1)$ or one compressor continuously running and the other one cycling on and off $(n=2)$. These surfaces are presented in figure 11 . The bold square represents the optimal frequency of $33.7 \mathrm{~Hz}$ for the example of for the ambient temperature and

In order to calculate the building supply temperature, the value of the internal frequency resulting from the control surfaces in Figure 11 is considered and equation (7) is solved for $\quad\left(2^{\text {nd }}\right.$ order equation, the negative root is the right solution). However, there are both an upper and a lower limit in the setpoint that should not be overpassed. The upper limit is $15^{\circ} \mathrm{C}$, the dew temperature. The water cannot be supplied to the building at a temperature higher than the dew temperature, otherwise the dehumidification in the rooms would not be possible. The lower limit is $7^{\circ} \mathrm{C}$. This limit is set in order to avoid freezing problems in the heat pump.

Looking at figure 10, it can be observed that the algorithm calculates values of outside of these limits. As far as the upper limit is concerned, there is no problem in setting a temperature lower than the one calculated. The energy savings will not be so important, but the user comfort will still be met. However, if 
the algorithm calculates a value of $\quad$ lower than $7^{\circ} \mathrm{C}$, but the setpoint is set to $7^{\circ} \mathrm{C}$, the user comfort will be unlikely to be met. That is the reason why, in case that this happens, the internal frequency should be recalculated by means of equation (10). Solving equation (10) for and considering a , will provide the corrected value of the frequency (higher than the previous) that will allow the system to meet the user comfort. Figure 12 shows a flow diagram of the optimized control implemented on the control board of the system.

Comparing the flow diagrams in figures 3 and 12, the differences between the former and the new control are clearly observed. On the one hand, the calculation of the external frequency is not modified with respect to the former control. The original equation coming from the original performance factor maps presented in [10] is kept. On the other hand, the calculations of and are coupled, since both of them affect the effectiveness of the fan coils. First, the value of the internal frequency ( ) is determined as a function the ambient temperature ( $\quad$ ) and the partial load ratio ( ) by means of equation (16). Then, using this value of , the value of the building supply temperature $(\quad$ ) is determined, also considering the value of , by means of equation (10). Finally, if the resulting value of is lower than $7^{\circ} \mathrm{C}$ (limit for heat pump freezing problems), is set to $7^{\circ} \mathrm{C}$ and is recalculated by means of equation (10). The corrected value of will be higher in order to balance out the effect of setting a setpoint temperature lower than that calculated by the algorithm. 


\section{RESULTS AND DISCUSSION}

Figure 13 depicts, for a typical cooling day, how the new optimized control works. It shows the evolution with time of some variables of the system for a single day operation in cooling mode, including the controlled variables.

The installation does not run continuously, but stops during the night. The period represented in Figure 13 corresponds to 13 hours, which is the time that the installation works every day ( $7 \mathrm{am}$ to $8 \mathrm{pm}$ ).

Figure 13a shows, from top to bottom, the variation of the pumps' frequencies ( and ) as a function of the partial load ratio ( ), represented on the secondary axis. It can be observed how the variables are directly proportional: the higher the partial load ratio, the higher the frequency set in the inverters. It can be observed that the values of frequency are only modified when the partial load ratio is recalculated at the end of each characteristic cycle, that is to say, in the moment when the compressor switches on again (as described in [14]). The cycles can be followed looking at the compressor consumption ( ) in figure 13b. This also applies for the calculation of the building supply temperature ( ), represented in figure 13b as well.

Figure 13b shows the heat pump power consumption ( ) on the secondary axis and the evolution of several temperatures on the primary axis: the building supply temperature calculated by the algorithm

( ), the actual experimental building supply temperature ( ) and the ambient temperature ( ). is the average value of the ambient temperature for the 5 minutes previous to the recalculation of . This average temperature is used in the equations instead of the instantaneous value of the ambient temperature.

As it can be observed, the actual tank temperature ( ) tracks the calculated building supply temperature ( ), which coincides with the setpoint of the heat pump in the range of setpoint temperatures $\left(7^{\circ} \mathrm{C}\right.$ to $15^{\circ} \mathrm{C}$ ). When the algorithm calculates a building supply temperature greater than $15^{\circ} \mathrm{C}$, the setpoint of the heat pump is set to $15^{\circ} \mathrm{C}$ due to the limit for dehumidification explained in figure 10 . This can be observed at the beginning of the morning and in the afternoon: while the calculated is greater than $15^{\circ} \mathrm{C}$, the actual tank temperature ( $\quad$ ) cycles around $15^{\circ} \mathrm{C}$. 
It can also be observed how and are inversely proportional. In the morning, when the ambient temperature is lower, a higher setpoint is set in order to supply warmer water to the building thus saving energy. By midday, as the outdoor temperature gets hotter, the water is supplied at a lower temperature so that the thermal demand is met. The frequencies are higher in this period as well (see figure 13a). Finally, in the evening, as the sun sets and the ambient temperature decreases, and so does the thermal load since some of the the users go back home, the algorithm calculates a higher again in order to save energy. The main target of this new optimized control was being able to meet user comfort while saving as much energy as possible. This new optimization algorithm was implemented and programmed in the control board of the system in late April of 2015, and it has been running during the whole cooling season (May to September 2015). For the time being, during the period devoted to the experimental campaign, positive feedback has been received from the users in the building regarding their thermal comfort. According to Spanish regulations [15], comfort conditions are defined as an acceptable range of indoor temperature (T) and relative humidity $(\mathrm{RH})$ which have been defined taking into consideration the metabolic activity of the people (1.2 met for sedentary metabolic activity, being 1 met equal to $58,2 \mathrm{~W} / \mathrm{m}^{2}$ ), their grade of clothing ( 0.5 clo in summer and 1 clo in winter, being 1 clo equal to $0,155 \mathrm{~m}^{2} \mathrm{~K} / \mathrm{W}$ of clothes' thermal resistance), and the Predicted Percentage of Dissatisfied people (PPD) between $10 \%$ and $15 \%$. According to these conditions, comfort conditions are $\mathrm{T}=[23 ; 25]^{\circ} \mathrm{C} ; \mathrm{RH}[45,60] \%$ for cooling mode and $\mathrm{T}=[21 ; 23]^{\circ} \mathrm{C} ; \mathrm{RH}$ $[40,50] \%$ for heating mode. Figure 14 a presents the evolution of the temperature and relative humidity of two representative rooms when the previous control algorithm was working in a hot summer day of July. As it can be observed, the indoor temperature and relative humidity take values of $27^{\circ} \mathrm{C}$ and $70 \%$ approximately which are not acceptable and lie outside the comfort range for cooling mode. On the other hand, Figure 14b shows the evolution of the temperature and relative humidity for the same rooms in a similar hot day in July with the new updated control algorithm working. As it is shown, both the indoor temperature and relative humidity in the rooms correspond to comfort conditions $\left(\mathrm{T}=[24 ; 25]^{\circ} \mathrm{C} ; \mathrm{RH}=50 \%\right)$. In addition to this, the plan is to conduct a survey giving some questionnaires to the users at the end of the cooling season in order to check the degree of comfort that was achieved through this new algorithm. 
Regarding energy savings, Figure 15 shows these results for cooling mode (May to September 2015). Preliminary results for a few days in late April 2015 were obtained also for heating mode during the tuning up of the new optimized algorithm in the control board of the system. However, they are not representative days and this is why they are not considered in this paper. In the coming heating season the impact of new updated optimized control algorithm will be further analised and more results for heating mode will be available.

In order to carry out a proper energy optimization analysis, the optimized control has been compared to a standard control consisting of a temperature setpoint of $7^{\circ} \mathrm{C}$ and $50 \mathrm{~Hz}$ of frequency for both circulation pumps. It should be said that this standard control was slightly different in previous works due to specifications in GROUND-MED project, where the minimum setpoint allowed was $10^{\circ} \mathrm{C}$ in according to the targets of the project [16]. An automatic control has been implemented in the controller in such a way that the standard control is applied on odd days and the optimized control is used on even days. This is a good method for choosing when to apply each control strategy and obtaining in the end $50 \%$ of the days working with each one.

Figure 15a shows the values of the from to , calculated as described in [11], for the period when the experimental test campaign was carried out during cooling mode in year 2015. considers only the heat pump consumption, includes also the consumption of the external circulation pump and finally adds the consumption of the internal circulation pump. The daily performance factor $3(\quad)$ corresponds to the daily performance factor of the system $(\quad)$, since the fan coils are not included in the energy optimization strategies.

The alternation of standard and optimized days can be clearly observed in Figure 15. For instance, looking at (triangles), the values are around 3 for the days when the standard control was applied, and around one point higher for those when the optimized control was applied, which would represent an improvement of $33 \%(\quad)$.

Figure 15a shows DPFs calculated for each day in the analyzed period (cooling mode from May to September 2015). Getting together the standard days on one hand, and the optimized days on the other hand, a kind of Seasonal Performance Factor (SPF) can be obtained for each case. In this way the improvement achieved by the optimized control when compared to the standard control can be analyzed for 
cooling mode. Figure $15 \mathrm{~b}$ presents this comparison. It can be seen that the improvement in is not representative. Although the variation of the temperature setpoint of the heat pump can lead to the heat pump consuming less energy, the flow rates of the circulation pumps are also decreased, hence making the compressor of the heat pump consume more energy.

The maximum improvement is observed in because it takes into account both circulation pumps, the consumption of which is being optimized. In fact, this is the objective of the optimization strategies regarding energy consumption: to optimize the seasonal performance factor of the system (

\section{). A $33 \%$ improvement is obtained in .}

The methodology presented in this paper has been applied to the particular case of the GSHP installation located at the Universitat Politècnica de València. Nevertheless, it is perfectly applicable to any GSHP installation following the same in situ experimental methodology. The only extra information required is the thermal performance of the terminal units, which are fan coils in this particular case.

\section{CONCLUSIONS}

An experimental in situ optimization methodology for the water circulation pumps frequency of ground source heat pump systems was previously developed by the authors. Combining this strategy with an outdoor temperature reset strategy, an energy optimization algorithm was developed, implemented and tested in a geothermal experimental plant located at the Universitat Politècnica de València, Spain. Results showed around a 30\% improvement on the seasonal performance factor of the system ( ). However, after analyzing the users' feedback during a whole year of operation, it was concluded that the user comfort was not met under extreme weather conditions in summer.

An upgrading to this optimized control is presented in this paper. This optimized control is based on coupling the calculations of the internal frequency and the supply building temperature so that the fan coils have a capacity such as to cover the thermal demand and meet the user comfort even in extreme weather conditions during summer. The calculation of both variables (internal frequency and building supply temperature) is determined as a function of both the ambient temperature (outdoor conditions) and the partial load ratio of the system (thermal load conditions), making the geothermal system smart and adaptive to actual operating conditions. 
First, the internal frequency is calculated as a function of the ambient temperature and the partial load ratio. Then, with this calculated value of frequency, the supply building temperature is determined in order to meet the user comfort. If the calculated building supply temperature is out of the feasible range of operation setpoint for the heat pump, it is set to the limit value and the internal frequency is corrected so that the user comfort is always met, keeping the system in its optimal operation point. This optimization methodology is perfectly applicable to any other ground source heat pump installations.

The new optimized control was developed, implemented and tested during the whole cooling season (May to September 2015). Results show an improvement of $33 \%$ and the feedback about comfort has been positive, as the system was able to keep measured values of temperature and relative humidity in two selected representative rooms, inside the acceptable comfort range of $\left[23 ; 25^{\circ} \mathrm{C}\right]$ and $[45 ; 60 \%]$ respectively, according to Spanish regulations. Further work will be done during the experimental campaign planned for the coming heating season, and the feedback from users and comfort conditions (temperature and relative humidity) will also be analyzed in heating mode.

\section{ACKNOWLEDGEMENTS}

This work was supported by the "Programa de Ayudas de Investigación y Desarrollo (PAID)" of the Universitat Politècnica de València. This work was also supported by the European FP7 project “Advanced ground source heat pump systems for heating and cooling in Mediterranean climate" (GROUND-MED).

\section{NOMENCLATURE}

\section{Symbol}

Specific heat at constant pressure

Frequency

Flow rate

Operation state of the heat pump unit

Heat capacity

Relative humidity

Temperature

Overall heat transfer conductance of the room

Electrical power

\section{Subscripts}

Air

Outdoor ambient

Average value 
Compressor

External circulation pump

Internal circulation pump

Fan coil

Maximum value

Minimum value

Nominal value

Room

Room 1

Room 2

Building supply

System

Outlet of the tank

Water

\section{Greek symbols}

Partial load ratio of the system

Effectiveness

$\begin{array}{ll}\text { Acronyms } \\ \text { GSHP } & \text { Ground source heat pump } \\ \text { GSHX } & \text { Ground source heat exchanger } \\ \text { PF } & \text { Performance factor } \\ \text { DPF } & \text { Daily performance factor } \\ \text { SPF } & \text { Seasonal performance factor }\end{array}$

\section{REFERENCES}

[1] Urchueguía, J.F., Zacarés, M., Corberán, J.M., Montero, Á., Martos, J. and Witte, H.: Comparison between the energy performance of a group coupled water to water heat pump system and an air to water heat pump system for heating and cooling in typical conditions of the European Mediterranean Coast, Energy Conversion and Management, 49(10), (2008), 2917-2923.

[2] Fahlén, P. and Karlsson, F.: Improving efficiency of hydronic heat pump heating systems, 21st International Congress of Refrigeration, Washington, USA, (2003).

[3] Fahlén, P. and Karlsson, F.: Optimizing and Controlling Media Flows In Heat Pump Systems, 8th IEA Heat Pump Conference, Las Vegas, USA, (2005).

[4] Bernier, M. and Bourret, B.: Pumping Energy and Variable Frequency Drives, ASHRAE Journal, 41(12), (December, 1999), 37-40.

[5] Brodrick, J.R. and Westphalen, D.: Uncovering Auxiliary Energy Use, ASHRAE Journal, 43(2), (February, 2001), 58-61. 
[6] Bsnhfleth, W.P. and Peyer, E.: Variable primary flow chilled water systems: potential benefits and application issues, Report ARTI-21 CR/611-20070-01prepared for the Air-Conditioning and Refrigeration Technology Institute, Arlington, Virginia, US.

[7] Edwards, K.C. and Finn, D.P.: Generalised water flow rate control strategy for optimal part load operation of ground source heat pump systems, Applied Energy, 150, (2015), 50-60.

[8] Del Col, D., Azzolin, M., Benassi, G. and Mantovan, M.: Experimental analysis of optimal operation mode of a ground source heat pump system, Energy Procedia, 45, (2014), 1354-1363.

[9] Montagud, C., Corberán, J.M. and Montero, Á.: In situ optimization methodology for the water circulation pumps frequency of ground source heat pump systems, Energy and Buildings, 68, (2014), 42-53.

[10] Cervera-Vázquez, J., Montagud, C. and Corberán, J.M.: In situ optimization methodology for the water circulation pumps frequency of ground source heat pump systems: Analysis for multistage heat pump units, Energy and Buildings, 88, (2015), 238-247.

[11] Cervera-Vázquez, J., Montagud, C. and Corberán, J.M.: Analysis of the energy performance and control optimization of a GSHP installation, ASHRAE Transactions, 120 (2), (2014), 334-345.

[12] Ruiz-Calvo, F. and Montagud, C.: Reference data sets for validating GSHP system models and analyzing performance parameters based on a five-year operation period, Geothermics, 51, (2014), 417-428.

[13] Montagud, C. and Corberán, J.M.: Caracterización experimental del comportamiento de una bomba de calor geotérmica agua-agua reversible de alta eficiencia, VI Congreso Ibérico y IV Congreso Iberoamericano de Ciencias y Técnicas del Frío, Madrid, Spain, (2012). (Spanish)

[14] Ruiz-Calvo, F., Cervera-Vázquez, J., Montagud, C. and Corberán, J.M.: Cálculo de parámetros de control de un sistema de climatización en tiempo real: factor de carga parcial, VII Congreso Ibérico y V Congreso Iberoamericano de Ciencias y Técnicas del Frío, Tarragona, Spain, (2014). (Spanish)

[15] Real Decreto 1027/2007, de 20 de julio, por el que se aprueba el Reglamento de Instalaciones Térmicas en los Edificios (RITE): IT 1.1.4.1.2. Temperatura operativa y humedad relativa. (Spanish regulations)

[16] GROUND-MED: http://www.groundmed.eu; (Last access: July 2015) 
Figure 1: Ground Source Heat Pump system diagram [10].

Figure 2: maps as a function of pumps frequencies in cooling mode: (a) $\alpha=0.1$; (b) $\alpha=0.3$; (c) $\alpha=$ $0.5 ;(d) \alpha=0.8[10]$

Figure 3: Flow diagram of the former optimized control (cooling mode).

Figure 4: Fan coil effectiveness in cooling mode.

Figure 5: Correlations for the fan coil effectiveness in cooling mode.

Figure 6: $\quad$ as a function of for optimal (cooling mode).

Figure 7: a) as a function of ;b) as a function of (both for cooling mode)

Figure 8: Optimal value of $\quad$.

Figure 9: Resulting optimal with the new control compared to the former one.

Figure 10: Resulting optimal with the new control compared to the former one.

Figure 11: Control surfaces for .

Figure 12: Flow diagram of the new optimized control (cooling mode).

Figure 13: Variables and results of the optimized control on a typical cooling day: a) Partial load ratio and frequencies; b) Heat pump power consumption and temperatures.

Figure 14: Room temperature and relative humidity measurements on a typical cooling day. a) Values with the former control algorithm; b) Values with the new updated control algorithm.

Figure 15: a) Daily Performance Factors during cooling mode test campaign; b) Seasonal Performance Factor comparison: standard control versus optimized control for cooling mode. 


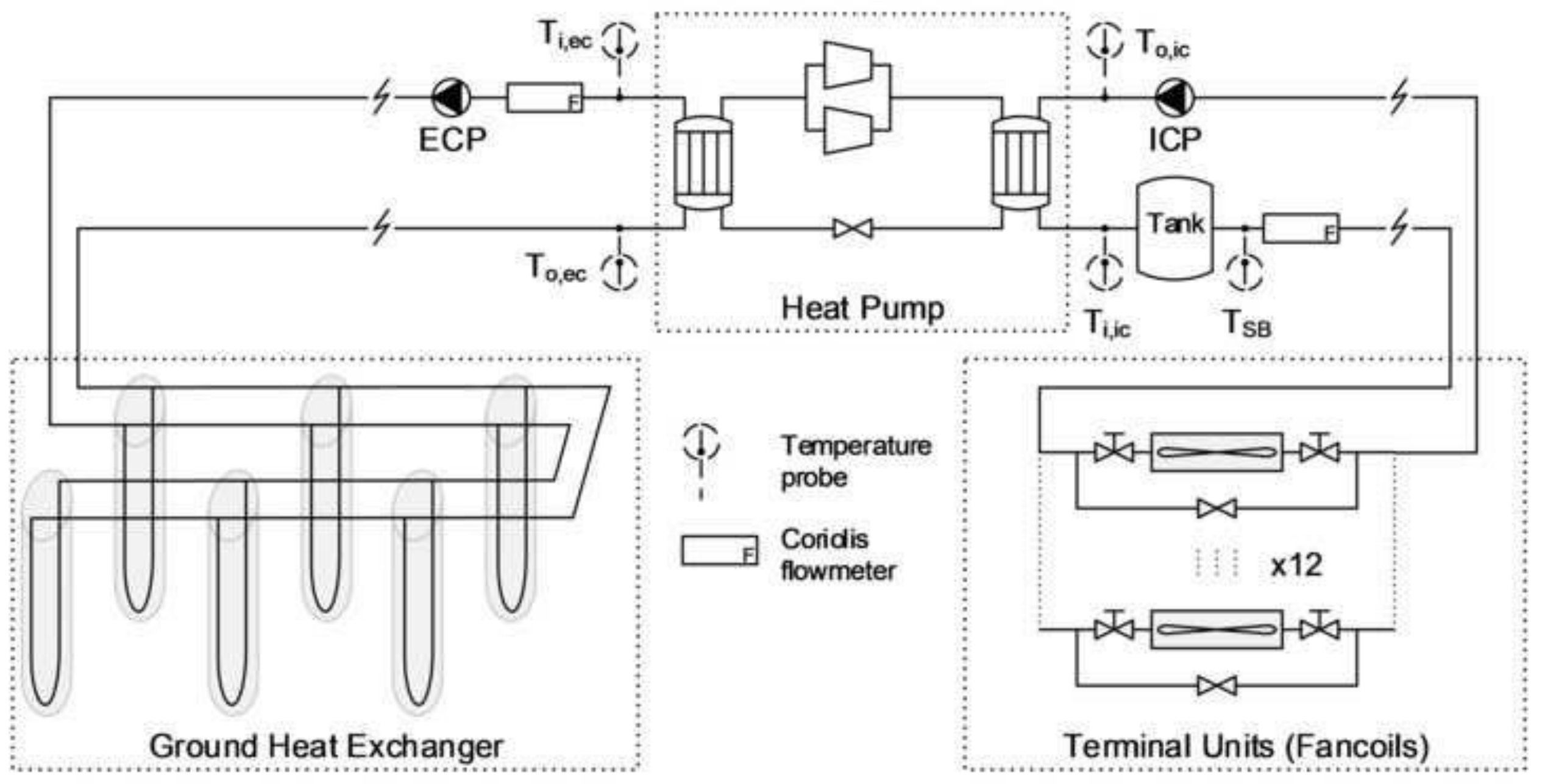



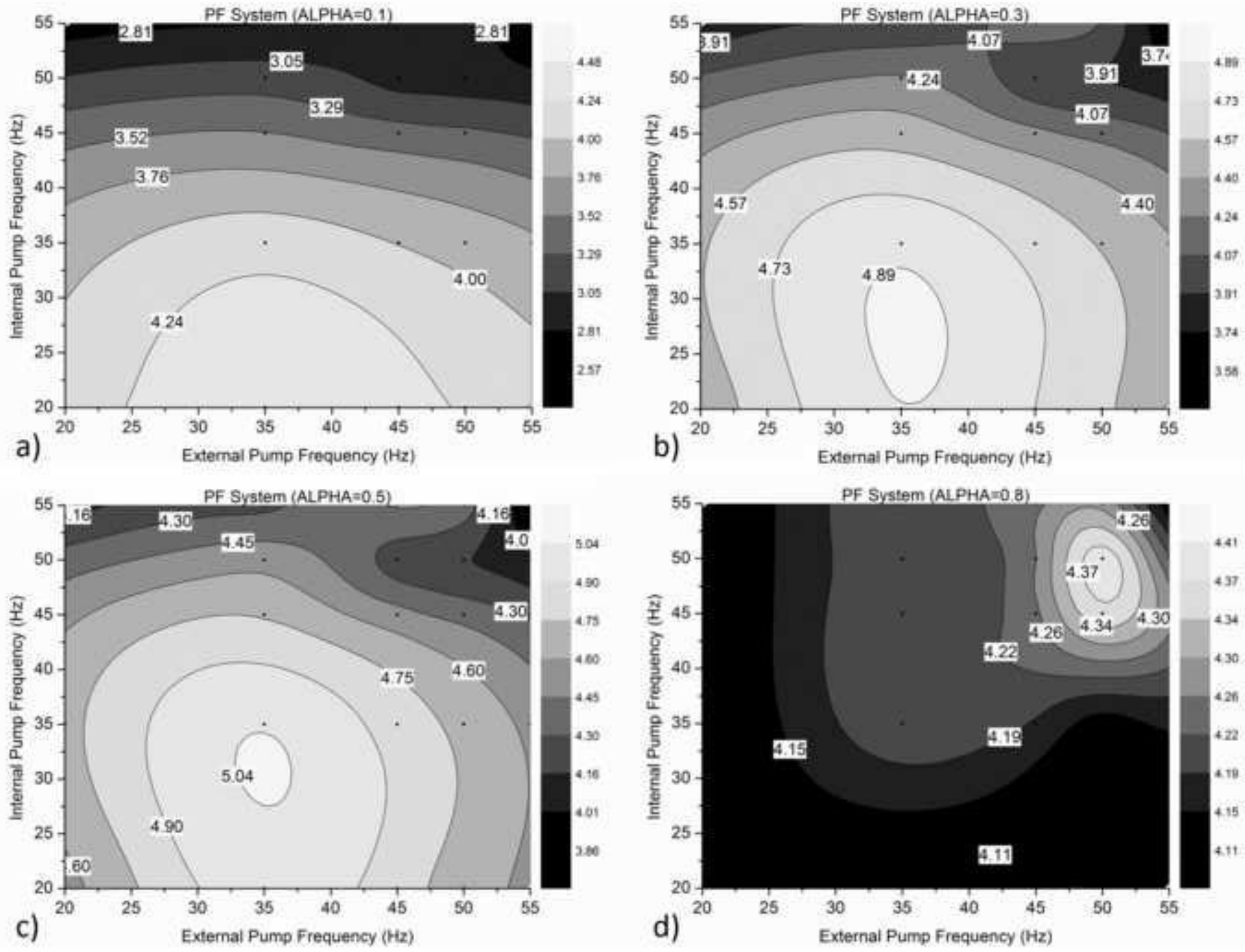


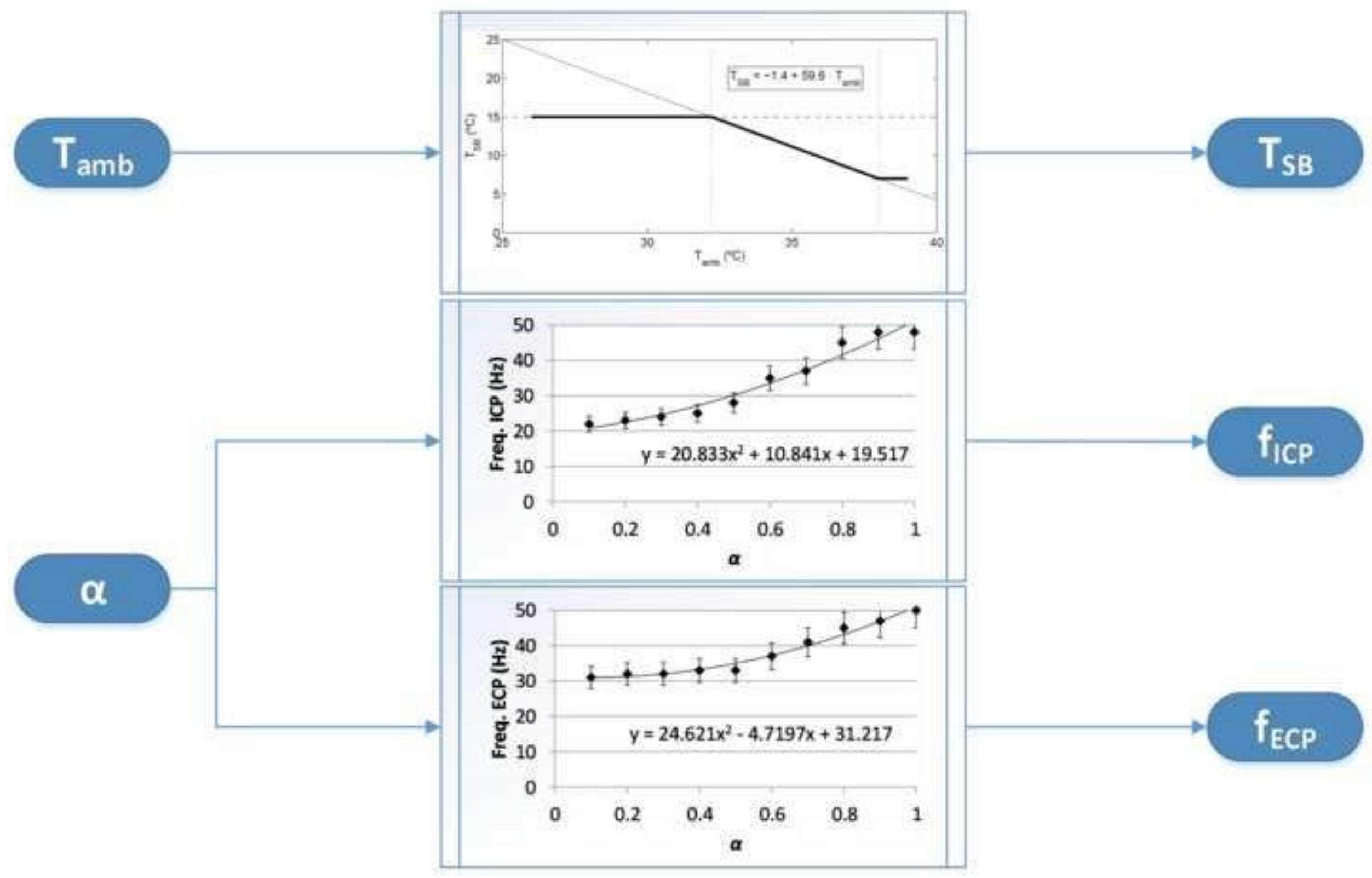




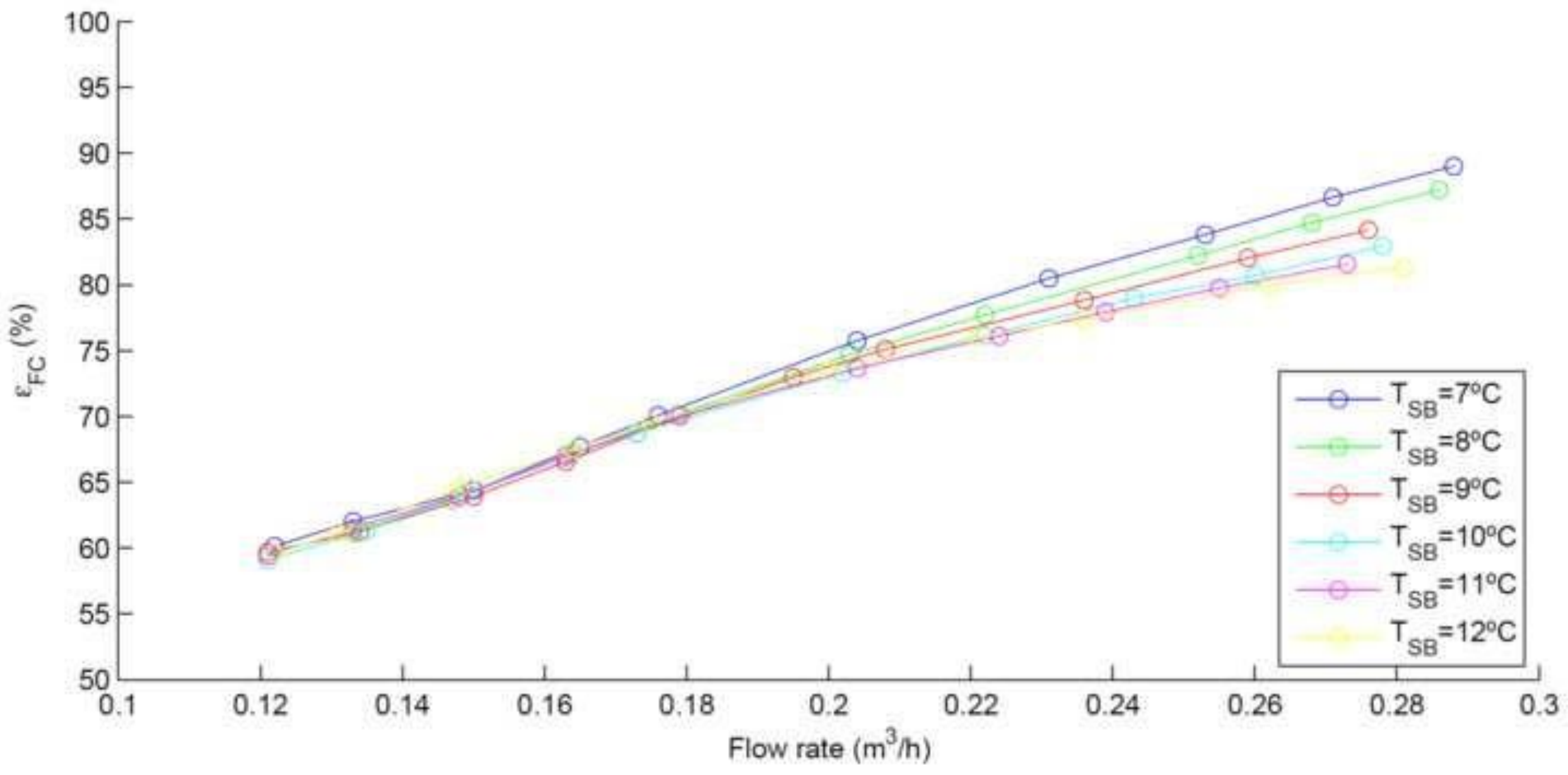


a) Correlation $E_{\mathrm{FC}} \mathrm{a}$

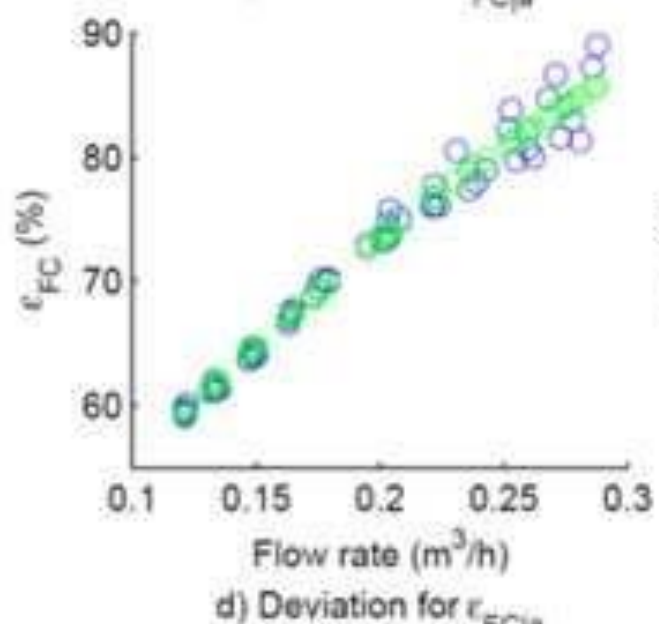

b) Correlation $\varepsilon_{F C D}$

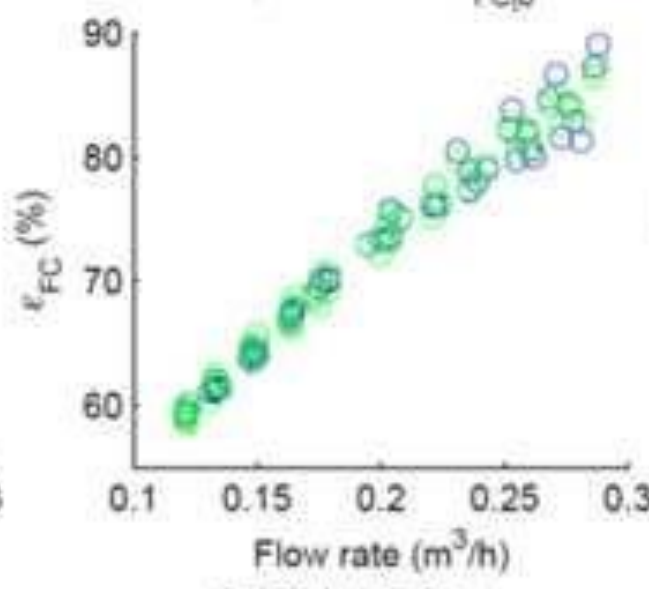

e) Deviation for $\varepsilon_{\mathrm{FCP}}$

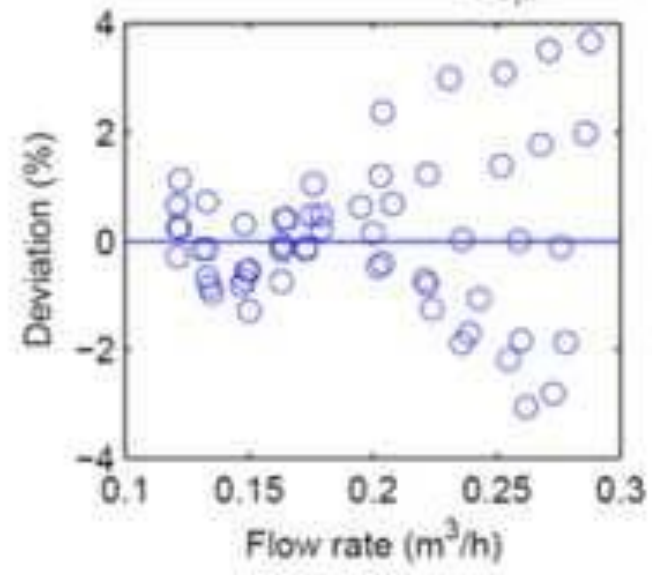

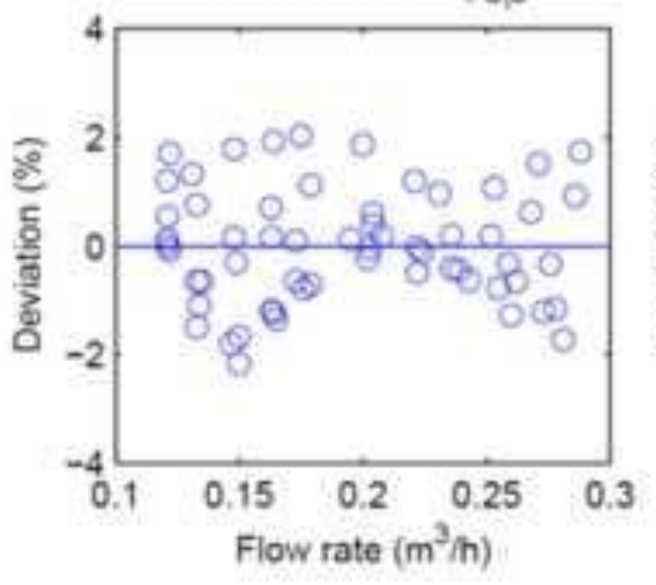
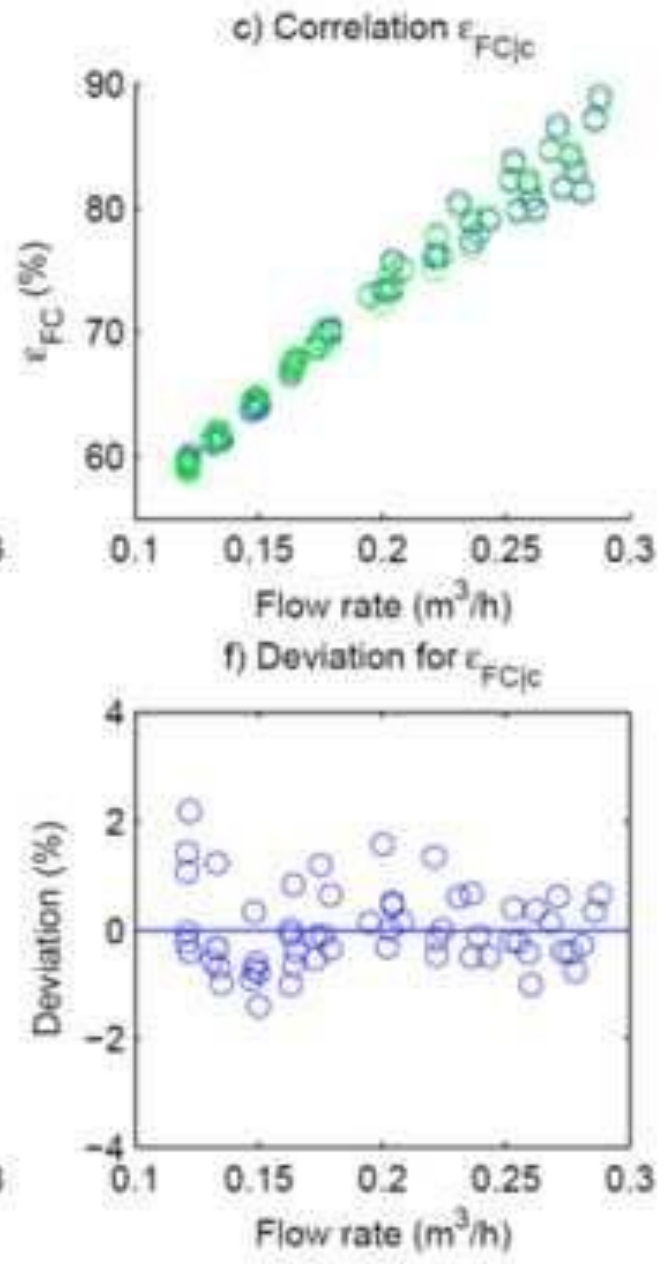

Calculated data set Correlated values 


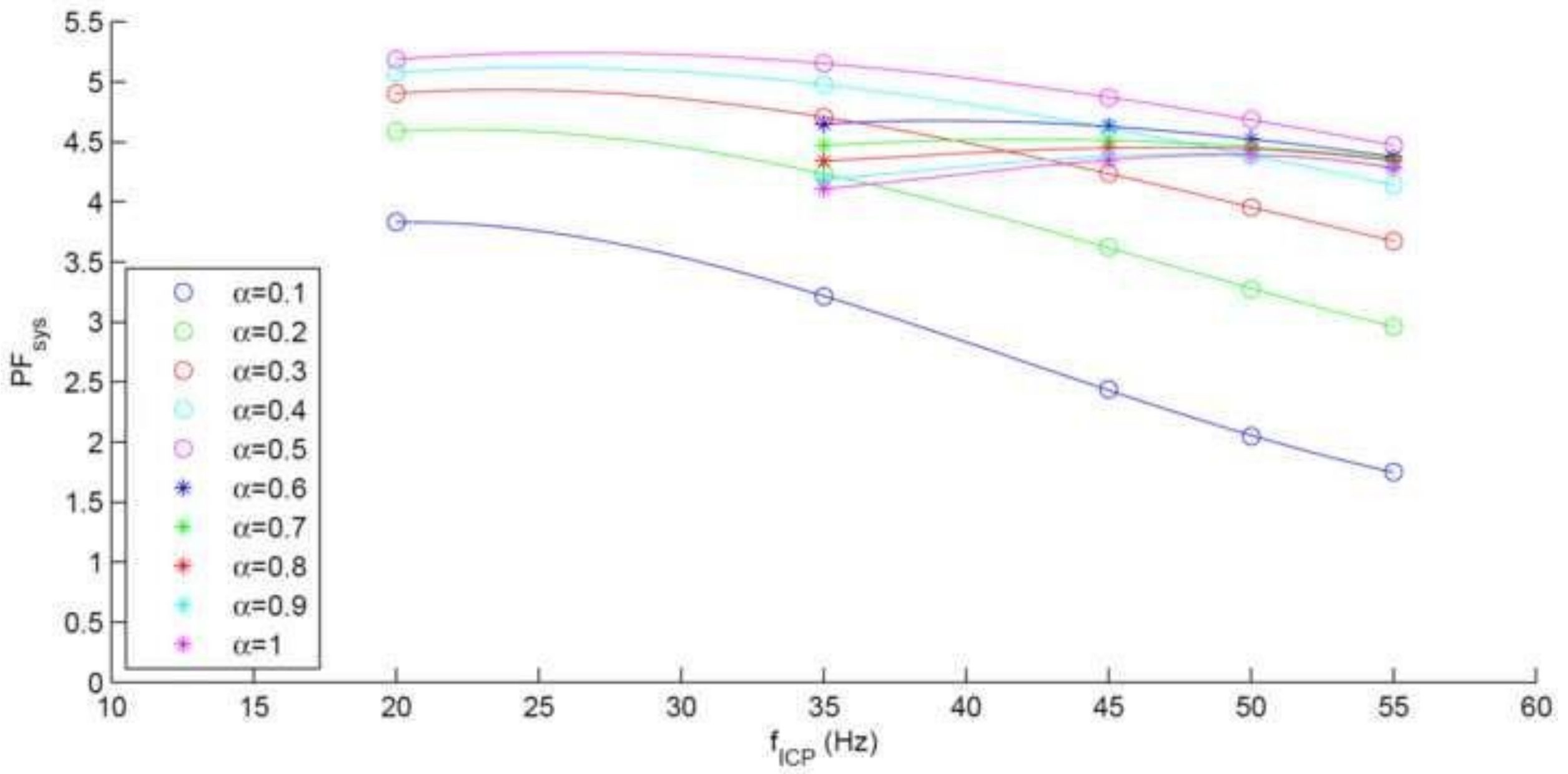



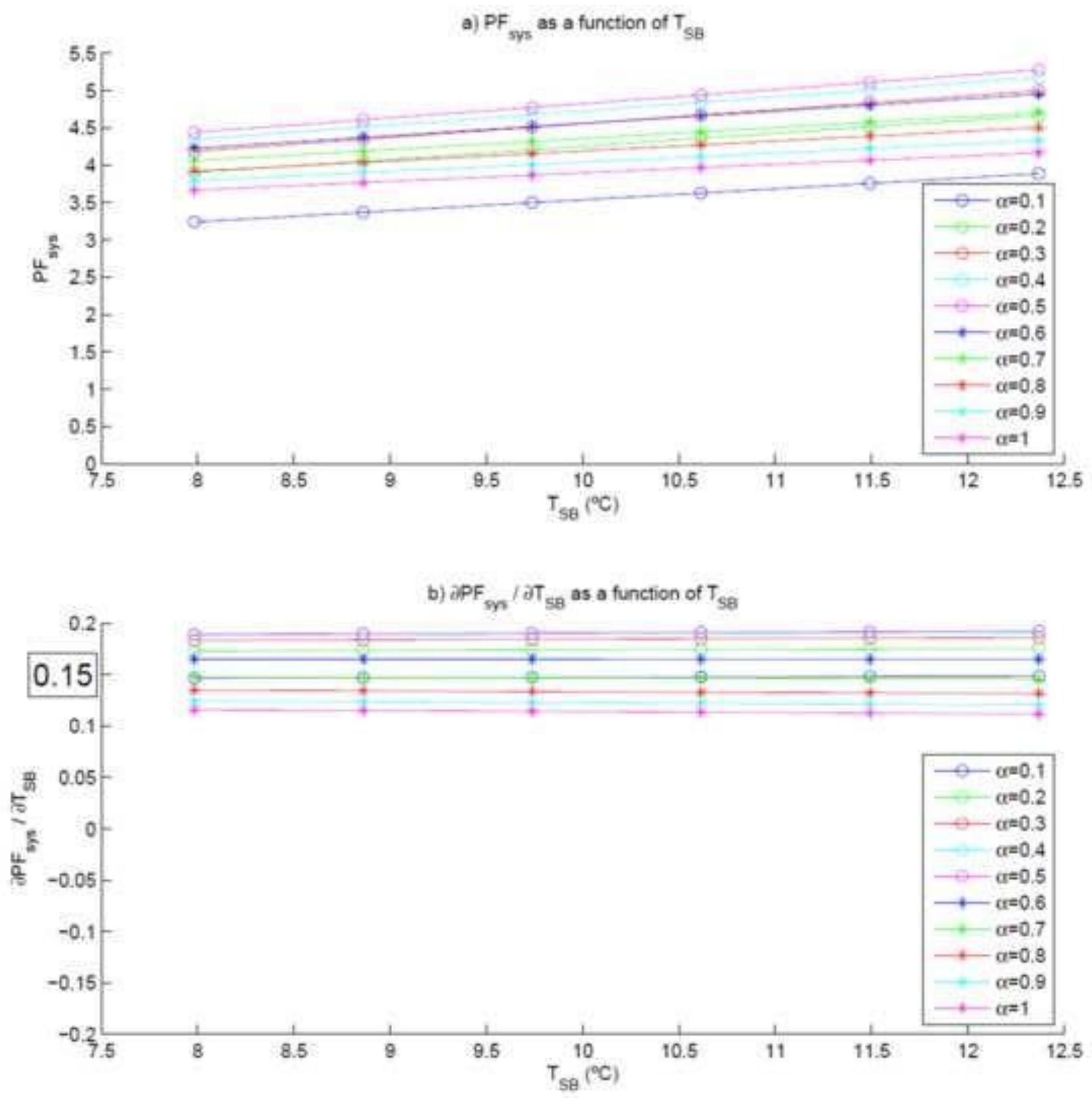

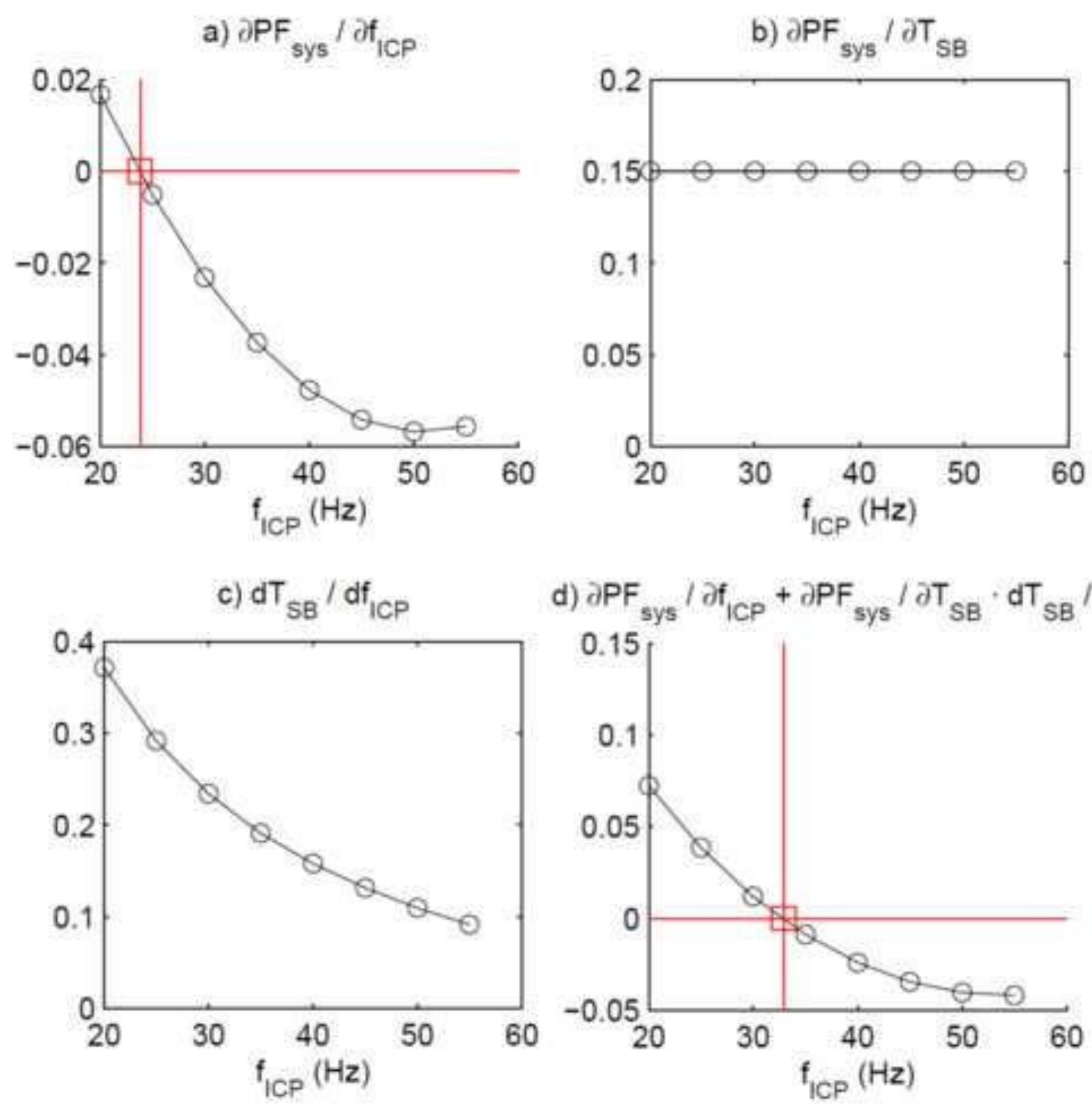

d) $\partial P F_{\text {sys }} / \partial f_{I C P}+\partial P F_{\text {sys }} / \partial T_{S B} \cdot d T_{S B} / d f_{I C P}$

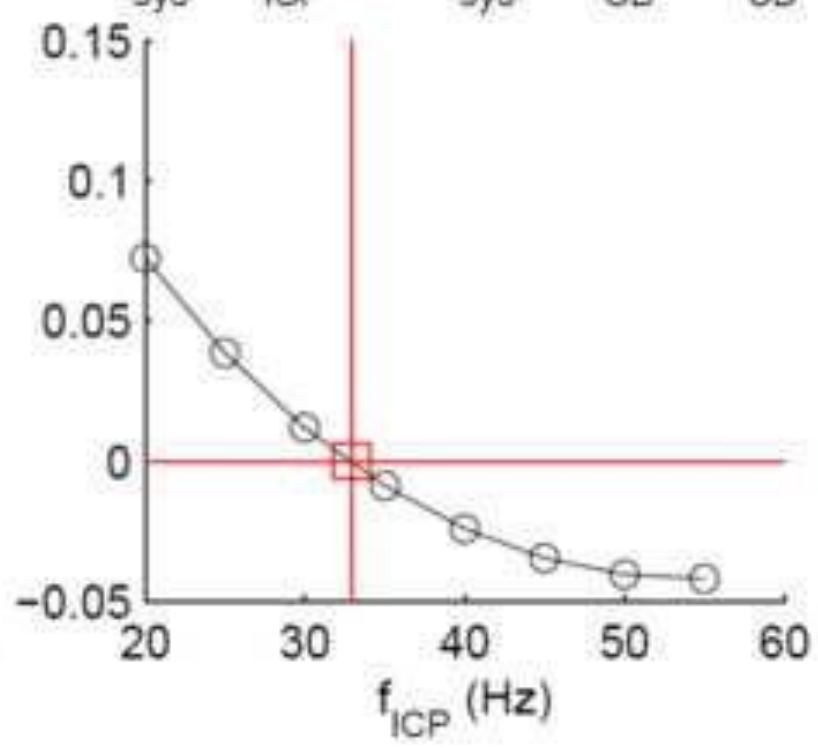




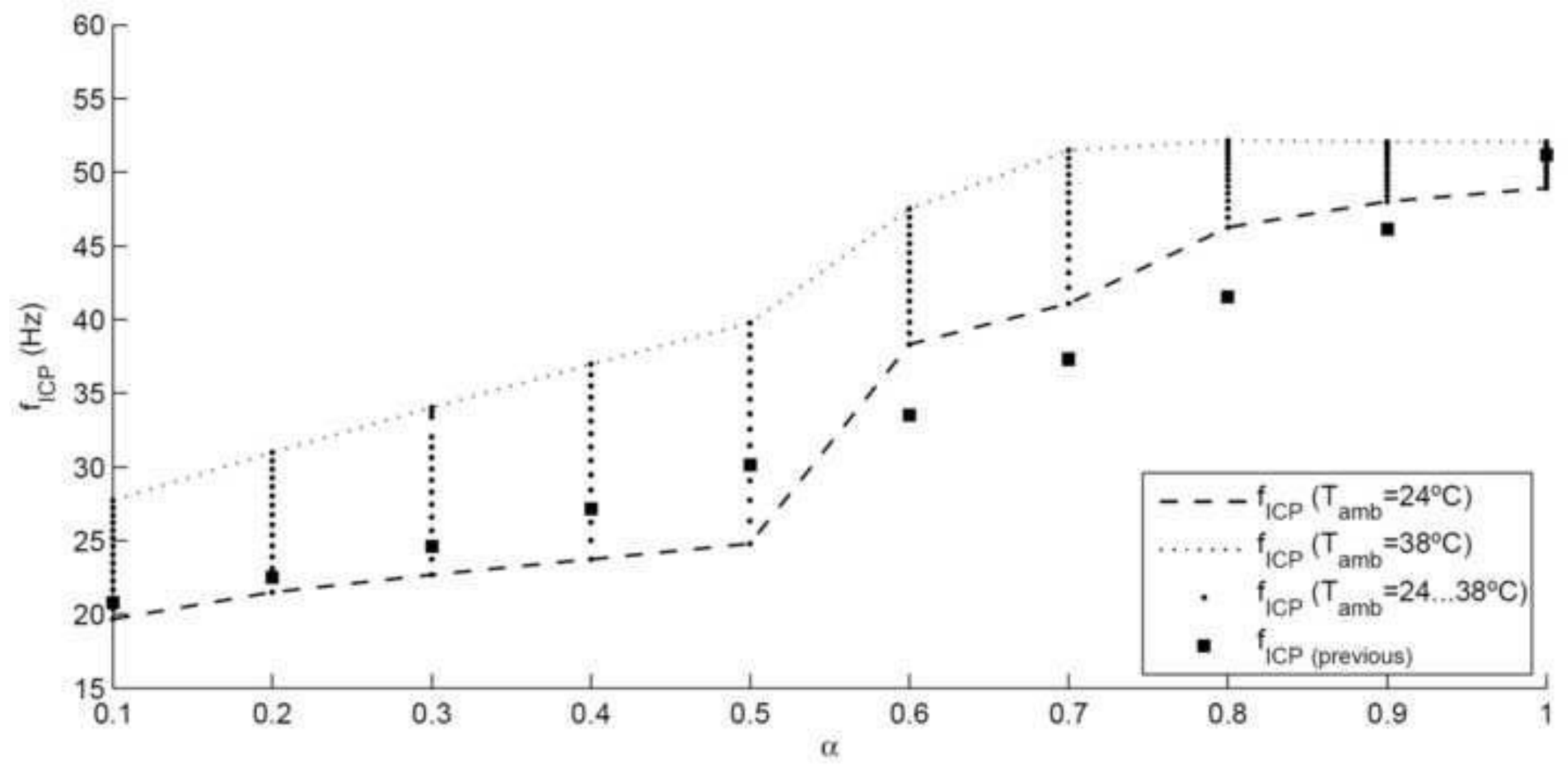




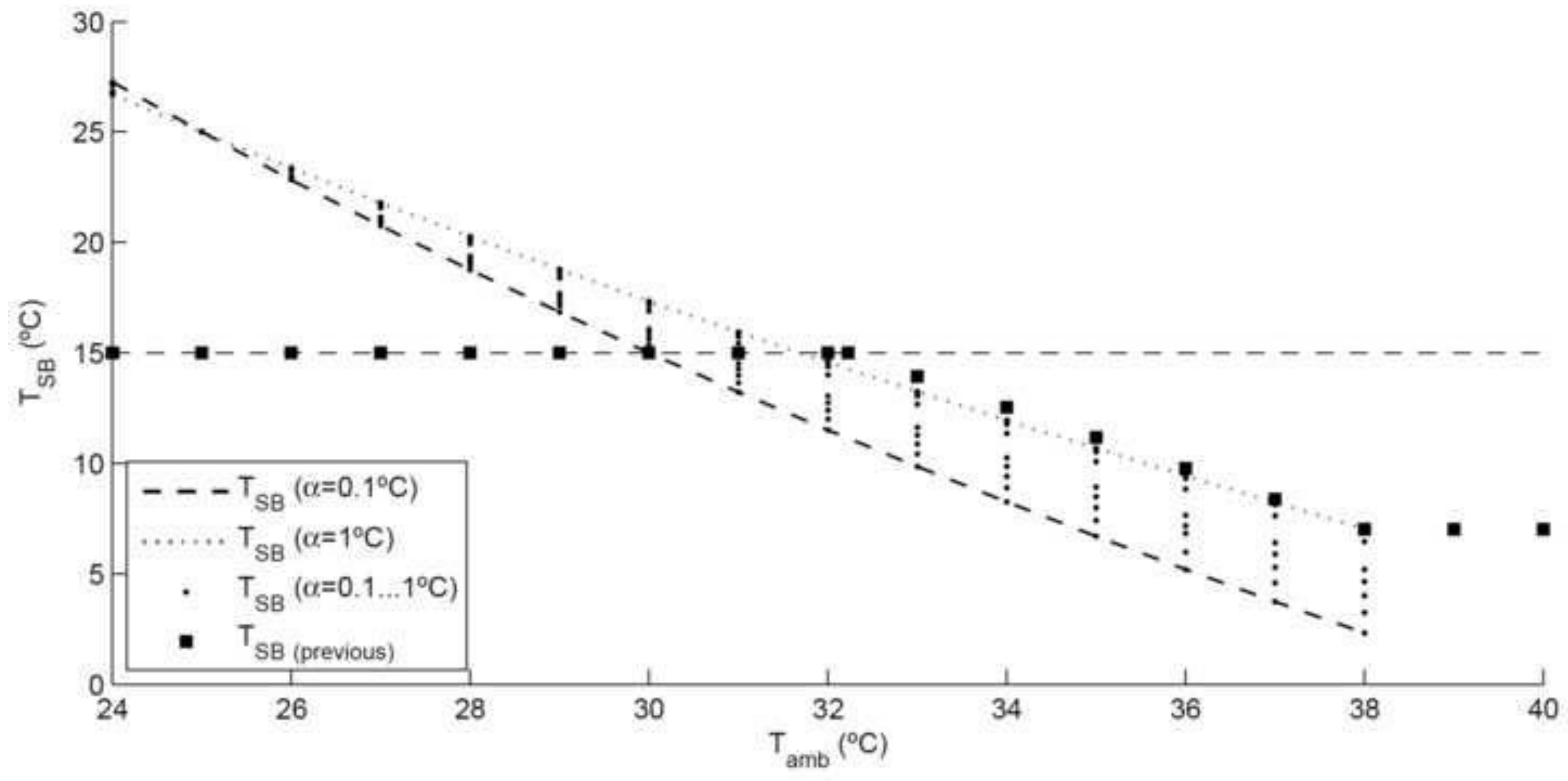




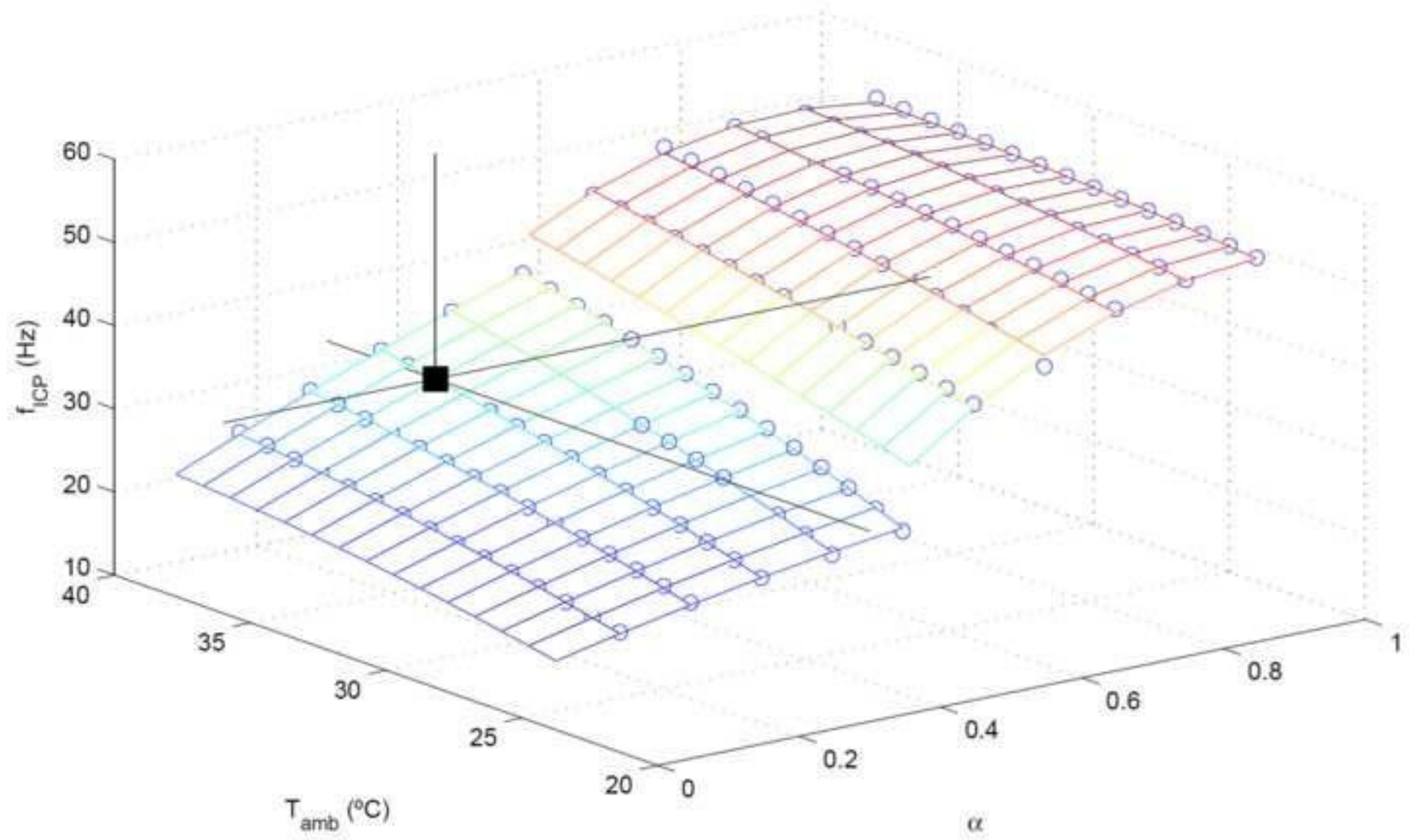




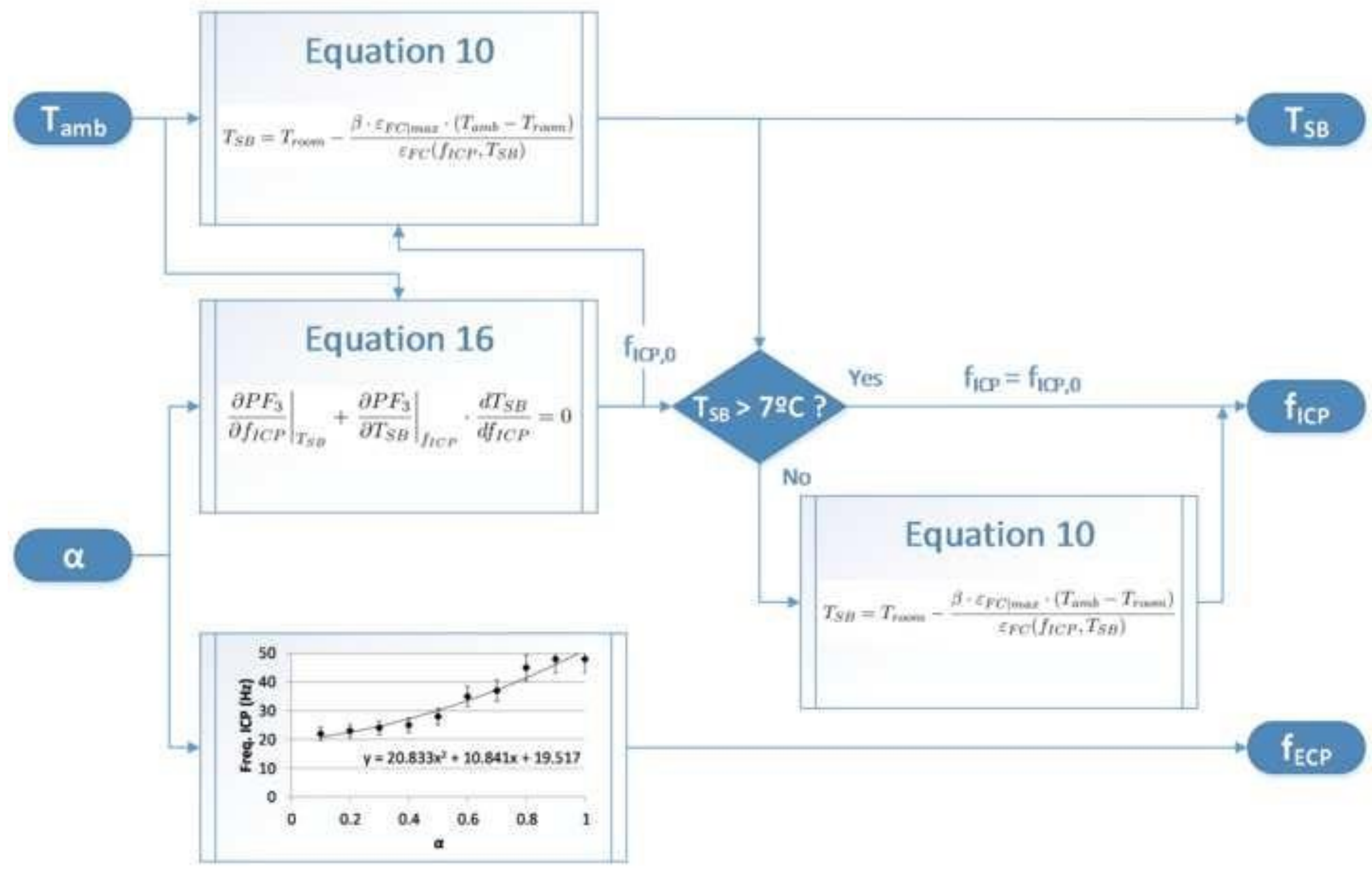




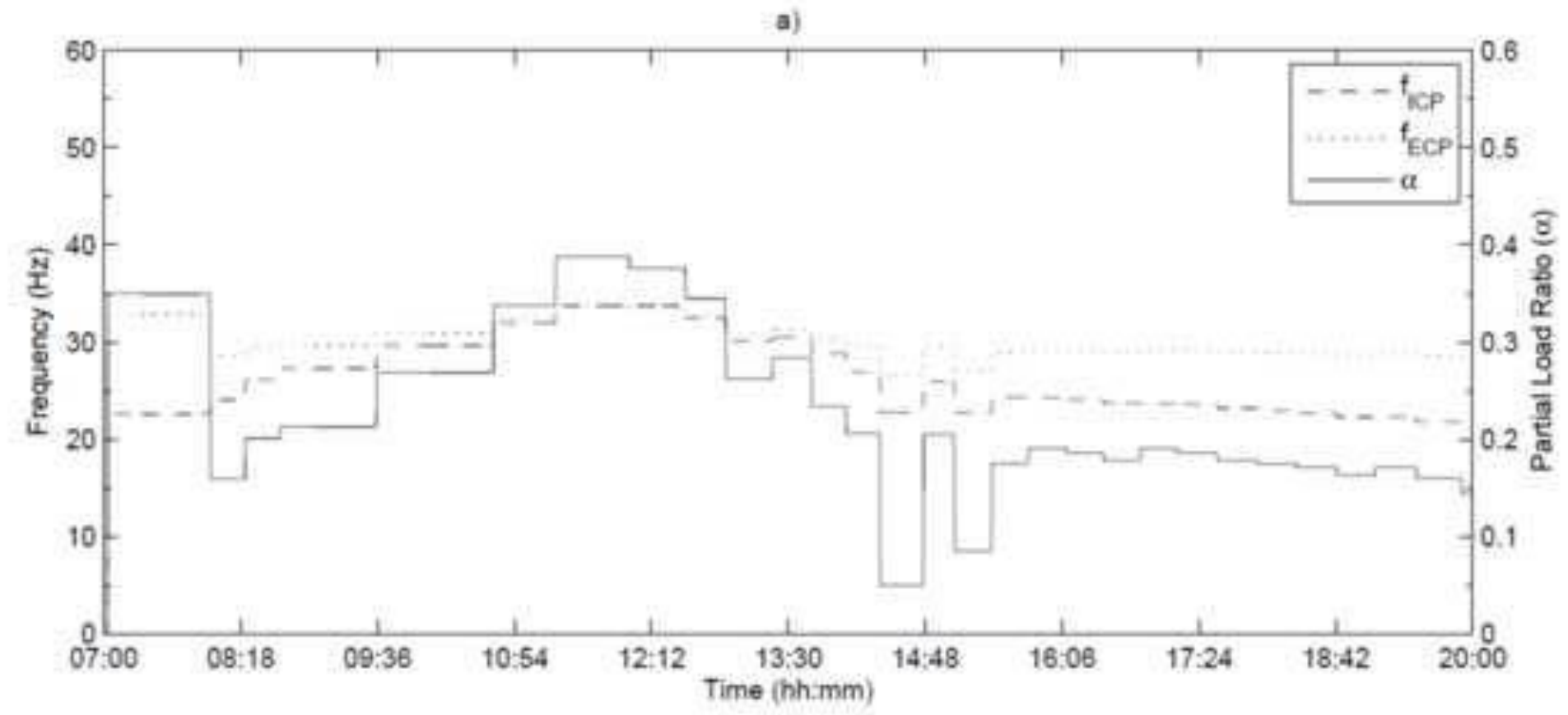

b)

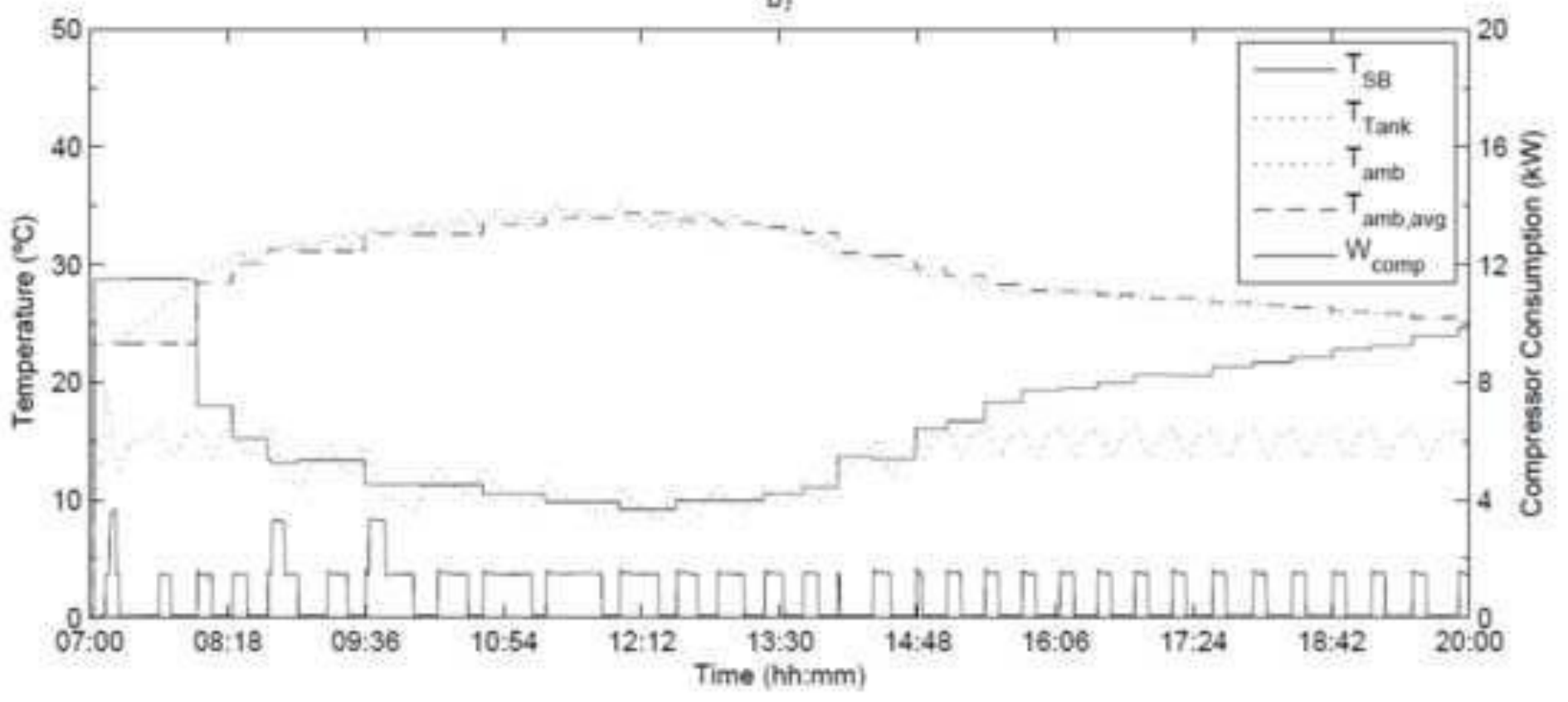


a)

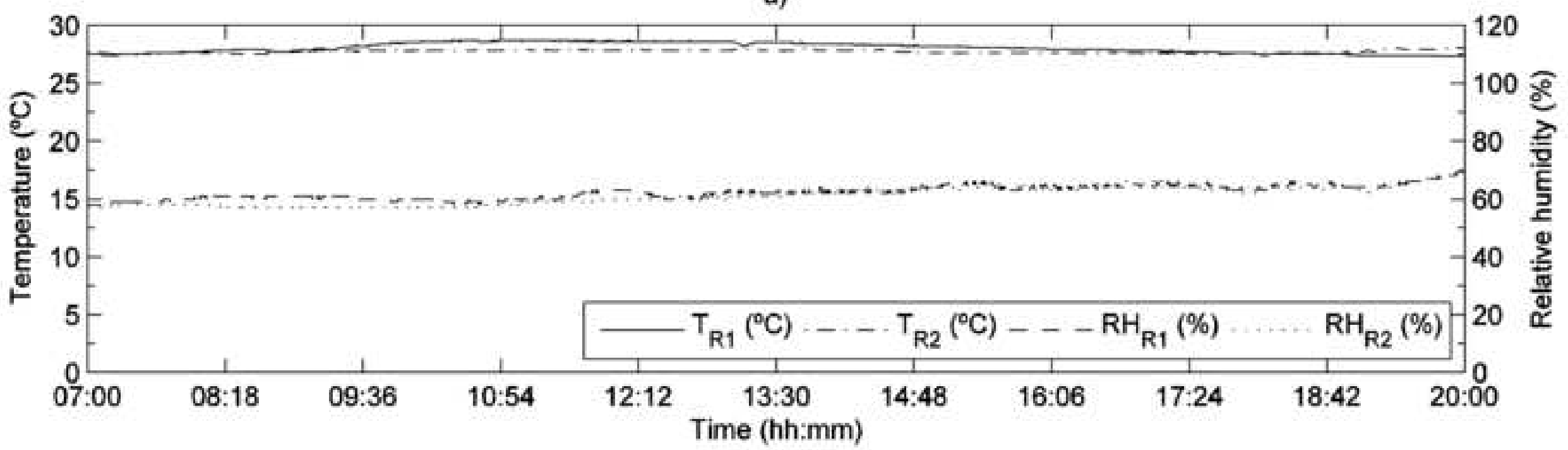

b)

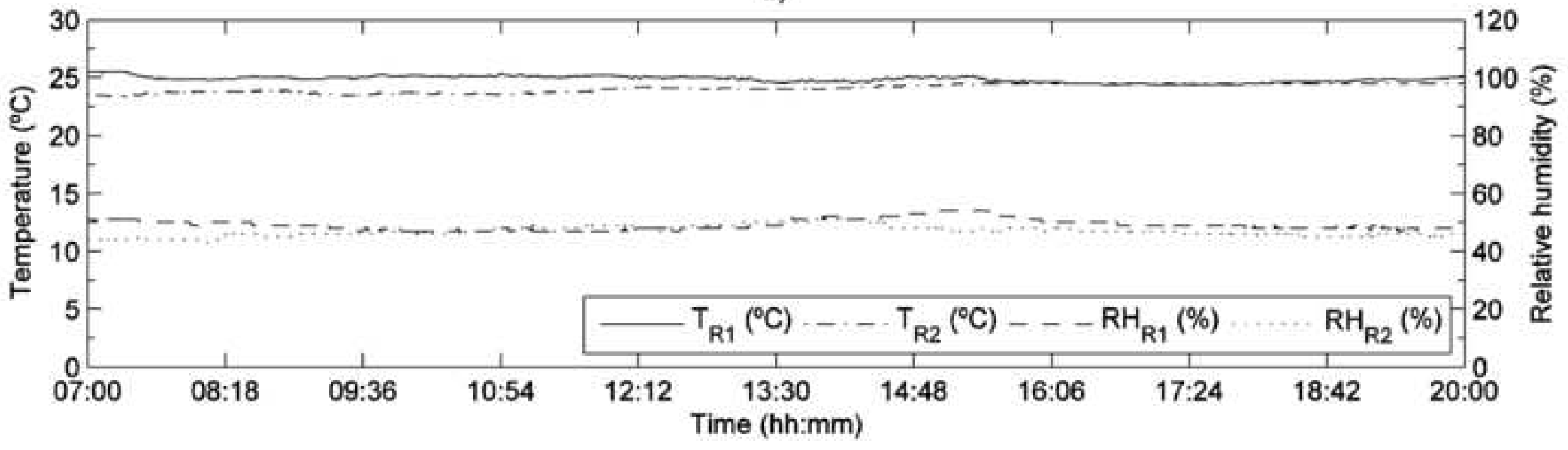



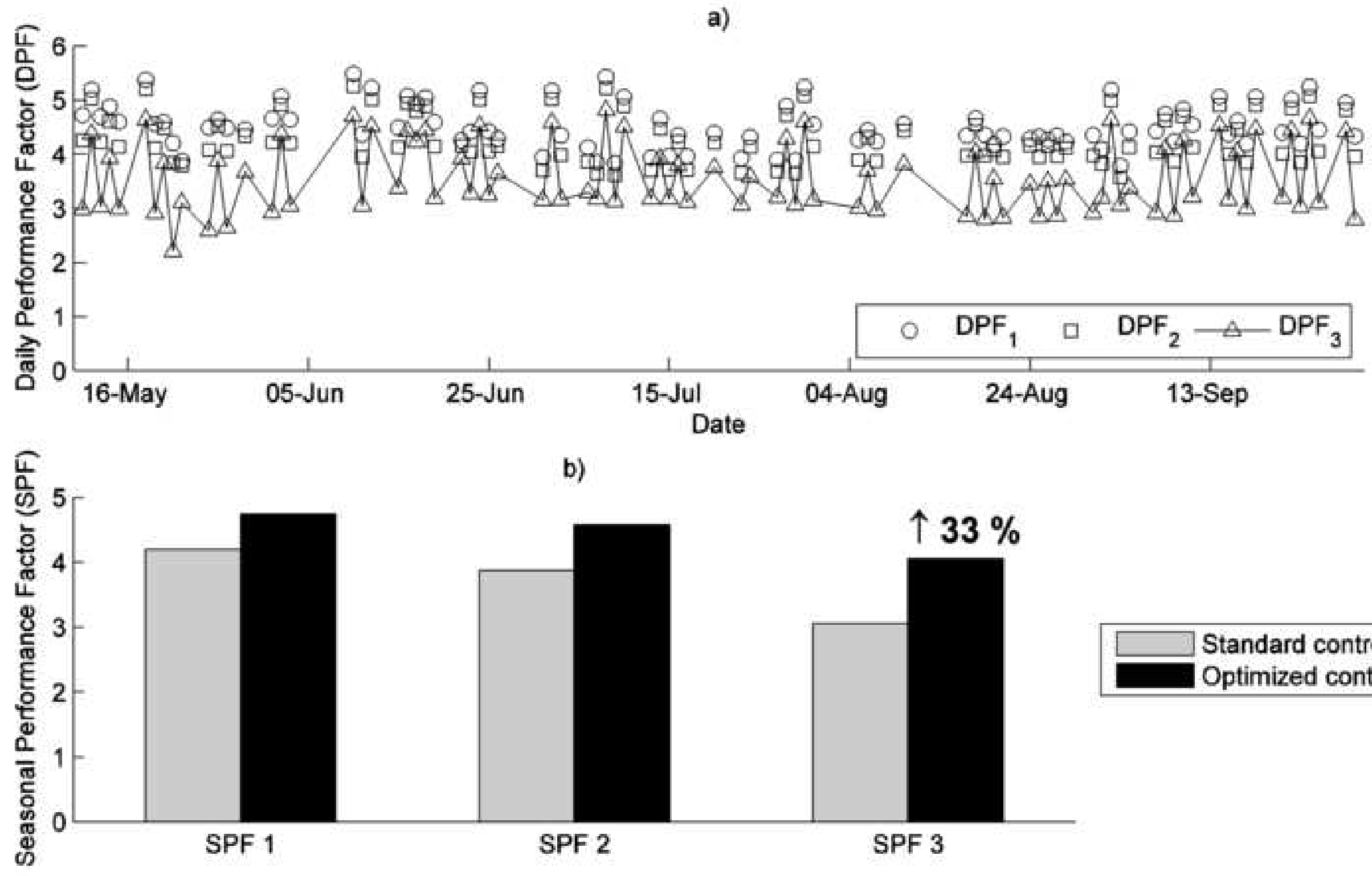